\title{
Orta Doğu Müzeciliğine Genel Bakış ve Ürdün Odağında Kültürel Miras ve Müzecilik Çalışmaları
}

\author{
An Overview of Middle Eastern Museology through Cultural Heritage and Museum \\ Studies with a Focus on Jordan
}

\author{
Ceren Güneröz ${ }^{*}$, Billur Tekkök Karaöz** $\mathbb{C}$
}

Öz

Arap Körfezi son on yılda ardı sıra açılan müzelerle uluslararası müze çevrelerinin gündemine yerleşmiştir. Bahreyn, Birleşik Arap Emirlikleri, Kuveyt ve Katar gibi Körfez ülkelerinde ve Ürdün gibi Orta Doğu coğrafyasının merkezinde müzelerin kültürel bir politika ile tanınmasını önerecek gelişmeler yaşanmıştır. Ulusal kimliği öne çıkaracak müzelerin açılmasıyla birlikte ulusal kültürel mirasın inşası hız kazanmıştır. Bu çalışma Ürdün'de Batı müzelerine benzer içeriklerle ulusal kültürü inşa etmeye çalışan Ürdün müzelerini derlemekte ve ülkedeki kültürel miras çalışmalarını çağdaş müzecilik yaklaşımları doğrultusunda tarihsel bir sıralamayla incelemektedir. Çalışmada Ürdün'de kültürel miras çalışmaları tarihsel gelişim ve uygulamalar dizgesinde ele alınmış, geleneksel Ürdün müzeleri ile çağdaş müze örnekleri tarihçeleri, misyon, vizyon ve müzecilik yaklaşımları doğrultusunda değerlendirilmiştir. Arkeoloji müzeleri, üniversitelere bağlı müzeler, çocuk müzesi ve Ürdün Ulusal Müzesi gibi örnekler değerlendirilmiş ve Orta Doğu'daki müzecilik hareketinin genel çerçevesi çizilmiştir. Ürdün müzelerinin sayısının ve çeşitliliğinin 1990'lardan itibaren artması olumlu bir gelişmedir ancak müzelerin mali zorluklarla ve nitelikli personel eksikliğiyle mücadele ettikleri saptanmıştır. Ülkede birkaç müze dışında eğitim birimleri bulunmaması, teknoloji kullanımına ihtiyaç duyulması, kurumlarla iş birliği sağlanamaması, konferans vb. tamamlayıcı etkinliklerin sayı ve sıklığının az olması, müzelerin kültür sektörünün diğer kuruluşlarıyla rekabet etmede zorlanması, referans kaynakların eksik olması, kültürel mirasa ilişkin kamuoyu oluşturulamaması sıkça karşılaşılan sorunlar olarak belirlenmiştir.

\section{Anahtar Kelimeler}

Müzecilik, Müze Eğitimi, Kültürel Miras, Orta Doğu, Ürdün

\begin{abstract}
The Arabian Gulf has gained international attention in museum studies due to the number of new museums with cultural policies that have opened within the last decade. In particular, there have been developments in the Gulf countries such as Bahrain, the United Arab Emirates, Kuwait, and Qatar, and in the center of the Middle East such as Jordan. This study highlights Jordanian museums that seek to show a unity of national culture with contents similar to Western museums and examines cultural heritage studies in Jordan in terms of both historical and contemporary museum approaches. In Jordan, cultural heritage studies evolved within a system of historical development and practices. This research compares traditional and contemporary Jordanian museums in line with their histories, mission, vision, and approaches to museology. Archeology museums, university museums, a children's museum, and the Jordan National Museum are evaluated, and a general framework is created for museology in the Middle East. It is pointed out that the increase in the number and variety of museums since the 1990 s is a positive development, but at the same time, museums are struggling with financial
\end{abstract}

* Sorumlu Yazar: Ceren Güneröz (Doç. Dr.) Ankara Üniversitesi, Güzel Sanatlar Fakültesi, Müzecilik Bölümü, Ankara, Türkiye. E-posta: ckaradeniz@ankara.edu.tr, ORCID: 0000-0001-5773-8557

** Billur Tekkök Karaöz (Prof. Dr.) Başkent Üniversitesi, Güzel Sanatlar Tasarım ve Mimarlık Fakültesi, Görsel Sanatlar ve Tasarım Bölümü, Ankara, Türkiye. E-posta: tekkok@gmail.com, ORCID: 0000-0001-8943-0215

Atıf: Guneroz, Ceren ve Tekkok Karaoz, Billur. “Orta Doğu Müzeciliğine Genel Bakış ve Ürdün Odağında Kültürel Miras ve Müzecilik Çalışmaları.” Art-Sanat, 16(2021): 221-252. https://doi.org/10.26650/artsanat.2021.16.0008 
difficulties and a lack of qualified staff. Moreover, common problems affecting museology in Jordan include a lack of educational units in museums other than a few major museums in the country, need for the use of modern technology, lack of cooperative studies, lack of complementary activities such as conferences and seminars, difficulty of competition with other organizations in the entertainment industry, lack of promotional materials, and insufficient public opinion in the fields of archeology and cultural heritage.

Keywords

Museology, Museum Education, Cultural Heritage, Middle East, Jordan

\section{Extended Summary}

Since ancient times, Middle Eastern civilizations have placed importance on collecting cultural artifacts and engaging in museum studies. In cultural heritage research, these lands have been the backyard of the West for many years. Though heritage links are not universally claimed or maintained in the Middle East, the West often voices such claims. Museum contents on Middle Eastern civilizations are largely found in the United States, Europe, and parts of other regions. The phenomenon of modern museums in the Middle East that resemble Western ones can be dated to the last quarter of the $19^{\text {th }}$ century.

With support from the West, including the opening of archeology museums in countries such as Lebanon, Egypt, Iraq, Afghanistan, and Morocco, the concepts of cultural heritage and national culture have begun to emerge in regional policy in the Middle East. In Middle Eastern museums, collection management and classification systems are applied with a Western understanding. Moreover, the museums conform to the schools of Western academic disciplines, not local perspectives. In the Arabian Gulf, which includes Iraq, Iran, Saudi Arabia, Kuwait, the United Arab Emirates (UAE), Oman, and Bahrain, cultural heritage and museum studies have grown since 1970 as a result of geographic research led by the UAE and Qatar. At the same time, Gulf museums have been built to showcase unity and national identity as positive outcomes of stability.

Today, the Arabian Gulf challenges Western traditional ideas through its own museology and art investments, where globalization and the postcolonial period previously shaped the region. The first museums founded in these countries were created by transforming the personal collections of people in executive and national leadership positions, and history museums were built by restoring existing historical buildings and highlighting national cultural heritage. Louvre Abu Dhabi, founded in 2007, brought world attention to the Arabian Gulf with art and cultural investments. The museum is promoted as having a "spirit open to the world," including the aim of fostering intercultural dialog with a hospitable approach in terms of both the cultures it represents and the diversity of its visitors. The museum, which was opened to represent a universal mission that cannot be limited by time and space with its own identity and dynamic in the region, is one of the largest shows of power in the Middle 
East in the $21^{\text {st }}$ century. Qatar, which is among the planned transformation countries in the Gulf, is the biggest rival of the UAE.

Just like other Arabic countries, colonialism in Jordan, which stands out due to its geopolitical location and rich cultural heritage in the Middle East, has left a permanent mark and sustainable legacy. In 1865, the Palestine Exploration Fund (PEF) was established by a group of Western academics and clergy. The purpose of PEF is to promote research in archeology and history, customs and traditions, culture, topography, geology, natural sciences and religion in the Palestine and Jordan region. Many archaeological sites have been made available to the tourist industry through PEF's work. Past and present approaches have been defined for the provision of archaeological resources as well as the establishment and diversification of national museums in colonial processes. Education in the field of cultural heritage has become widespread, and interest in museum types, museum education, and experimental archeology has increased. In this context, Jordan has made progress in establishing new specialized museums while improving existing ones.

Although Western scientists' interest in cultural heritage and archaeological research shifted to Palestine with the opening of the Palestinian Archaeological Museum in 1938, Jordan's participation in the Arab League Educational, Cultural and Scientific Organization in 1945 enabled the start of archaeological excavations by Jordanian scientists beginning in 1948; and this paved the way for Jordan to develop its own museums. In order to emphasize Jordan's archaeological heritage and build a heritage-linked national culture, the Jordanian Ministry of Tourism and Antiquities Unit, in particular, the Jordan Archaeological Museum, work in collaboration. These museums do not focus on educational or other social functions but rather serve as warehouses for objects. Despite the increase in museum studies, the adoption of a top-down approach in the management of archaeological sites by local authorities and stakeholders in Jordan has alienated local communities from the processes of cultural heritage studies, and residents living near ancient sites have become passive communities regarding site maintenance. The locals are not seen as allies in the protection of historical areas but instead as a damaging threat. To eliminate this perception, protect archaeological excavation sites, exhibit the artifacts obtained from excavations in a healthy condition, and carry out maintenance repairs, there is a need for new museums.

Though museums in Jordan are struggling with financial difficulties and a lack of qualified staff, the increase in their number and diversity since the $1990 \mathrm{~s}$ is a positive development. Currently, the most common problems of museology include a lack of educational units other than a few major museums in the country, need for technology use, lack of cooperation between museums and other institutions, low number and frequency of complementary activities such as conferences and seminars, difficulty 
of museums in competing with other institutions in the entertainment sector, lack of reference resources and promotional brochures, and lack of sufficient publicity in the fields of archeology and cultural heritage. In this study, cultural heritage studies in Jordan are discussed in terms of historical developments and practices; that is, Jordanian museums are evaluated in line with their history, mission, vision, and museology approaches. Examples such as archaeological museums, museums affiliated with universities, a children's museum, and the Jordan National Museum are evaluated, and a general framework is developed for the museology movement in the Middle East. 


\section{Giriş}

Orta Doğu, Arap ülkelerinin yoğunlukta olduğu geniş bir coğrafyadır. Buzan ve Wæver, Orta Doğu coğrafyasını üç alt bölüme ayırmaktadır: İlk bölgesel kompleks Misır, İsrail, Filistin, Ürdün, Lübnan ve Suriye’yi kapsayan Orta Doğu alt kompleksidir. İkinci bölgesel kompleks, Irak, İran, Suudi Arabistan, Kuveyt, Birleşik Arap Emirlikleri, Umman ve Bahreyn'i içine alan Arap Körfezi alt kompleksidir. Üçüncü bölgesel kompleks ise, Fas, Tunus, Cezayir ve Libya gibi ülkeleri kapsayan alt bölgedir ${ }^{1}$. Yeşilyurt tüm bu alt bölgesel komplekslerin, güvenlik alanında kendilerine özgü karşılıklı bağımlılık kalıplarına sahip olduklarını; bölgede temelde önemli siyasi konuların Arap-İsrail çatışması, Arap Birliği tartışmaları, siyasal İslam ve Basra Körfezi'nin güvenliği olduğunu vurgulamaktadır².

Orta Doğu, jeopolitik nedenlerle küresel siyasetin belirleyici bir aktörüdür. Dünyanın en büyük petrol rezervine sahip olan bölge, I. Dünya Savaşı ile özellikle petrolün endüstrileşmede önemli bir faktör hâline gelmesiyle, bat1lı güçlerin mücadele alanına dönüşmüş; İsrail Devleti'nin kuruluşundan itibaren çatışmaların odak noktası olmuştur. Akdeniz'e açılan bir kapı olan bölge aynı zamanda Basra Körfezi'nden yine büyük denizlere açılan ticari trafiğin en önemli merkezlerinden biridir. Farklı alt komplekslere ayrılan Orta Doğu zengin kültürel mirasıyla da dikkat çekmektedir. Bu bölge dünya tarihinde yazının bulunduğu Ur, Uruk, Lagaş gibi ilk şehir devletlerinin kurulduğu, ilk hukuk kurallarının ve yasaların yazıldı̆̆ı, Gılgamış, Yaratılış, Tufan gibi destanların kaleme alındığı, ilk ticaret kolonilerinin ortaya çıktığı coğrafyadır.

Orta Doğu uygarlıklarının antik dönemde müzecilik çalışmalarına önem verdiklerini gösteren çalışmalar bulunmaktadır. Thomason, bölgede en eski koleksiyonların MÖ 3000 yılında Mezopotamya'daki, Ebla'da (Suriye) toplanan arşivler olduğunu ifade etmektedir. Bu koleksiyon devlet işleriyle ilgili çok sayıda kayıt içermesinin yanı sıra konuya göre düzenlenmiş sözlükleri de içermektedir. MÖ 2000 yılında Larsa (Güney Irak) kentinde okullarda kopya nesnelerin eğitimde kullanıldığı belirlenmiştir. Thomason, Elam krallarının MÖ 14. yüzyılda Mezopotamya kentlerini işgal ederek birçok anıtı ele geçirdiklerini ve bu anıtları başkent Susa'da sergilediklerini de vurgulamaktadır³. Garrison, Babil kralı Nabonidus'un MÖ 6. yüzyılda Sippar kentinde adalet tanrısı Şamaş'a ait bir tapınakta eski eserleri sergilediğini ifade eder. Aynı şekilde Nabonidus'un kızı prenses Ennigaldi-Nanna'nın çok sayıda eski eseri müze hâline getirdiği ve bu eserlerin başlangıçta nerede bulunduklarını ve kime ait

1 Berry Buzan ve Ole Wæver, Regions and Powers: The Structure of International Security (Cambridge: Cambridge University Press, 2003), 90.

2 Nuri Yeşilyurt, “Ürdün’ün Bölgesel Konumu: Küçük Devlet Kavramı Çerçevesinde Bir İnceleme,” Ankara Üniversitesi Siyasal Bilgiler Fakültesi Dergisi 70/2 (2015), 378.

3 Thomason Allison, "The Impact of the Portable Integrating Minor Arts into the Ancient Near Eastern Canon," Critical Approaches to Ancient Near Eastern Art (Boston: Walter de Gruyter Inc., 2005), 133-157. 
olduklarını anlatacak şekilde etiket bilgilerinin yazıldığı ortaya çıkmıştır ${ }^{4}$. Bununla birlikte Nabukadnezar'ın kuzey sarayında koleksiyon odalarının yer aldığ 1 da bilinmektedir. Suter ise, Sümer Kralı Gudea'nın diorit taşından yapılmış çok sayıda heykelinin Güney Mezopotamya'daki bir sarayda MÖ 2. yüzyılda sergilendiğini yazmaktadır. $\mathrm{Bu}$ sergilerin küratörlüğünün bizzat krallar tarafından yapıldığı, kraliyet ve güç tanıtımı niteliğinde oldukları söylenebilir. Bölgedeki en ünlü antik museion, İskenderiye'de MÖ 290 civarında, İskender'in eski generali ve Mısır hükümdarı Ptolemy Soter tarafından kurulmuştur. Bu müzede el yazması parşömenler, doğa tarihi numuneleri ve sanat eserleri toplanmış ve sergilenmiştir. Günümüzde üniversitelerin araştırma ve uygulama merkezlerine benzeyen bu yapı bir müze enstitü görünümündedir'. Türkiye'de Pergamon'da (Bergama) Attalus I. Soter'in (MÖ 269179) yönetimi altında bir müze kurulmuştur. Kral Attalus bu müzeye kamusal alanlara kurulan büyük heykeller ve sanatçıların kopyalayabilecekleri yeni koleksiyonlar eklemiştir. Loftus, ilerleyen yüzyıllarda Orta Doğu coğrafyasında nesnelerin sanat ve bilim eğitiminde özellikle Şam, Bağdat ve Kahire kentlerindeki büyük medreselerde kullanıldığını ifade etmiştir ${ }^{6}$. Bisharat, kraliyet koleksiyonlarının, batılı örneklerde olduğu gibi, gücün ve meşrulaştırmanın bir bileşeni olarak toplandığını ve sergilendiğini belirtmektedir. Arapçada bu koleksiyonlara "dhakhira" (saray müzeleri) adı verilmiş ve bu koleksiyonlar sadece önemli ziyaretçilere açılmıştır" Loftus, mahkeme ve kraliyet belgeleri aracilığıla Abbasi (MS 750-1258) ve Fatimi (MS 909-1171) hükümdarlarının da cam eserler, oyma kaya kristalleri, tekstiller ve minyatürlerden oluşan kapsamlı sanat koleksiyonları topladıklarını vurgulamaktadır .

Orta Doğu'daki müzelerin tarihini kesin olarak belirlemek zordur. Bu bölgedeki müzecilik çalışmalarının Batı yazınında rastladığımız gibi kesin bir başlangıç noktası söz konusu değildir. Bu topraklar kültürel mirasın araştırılması süreçlerinde de uzun yıllar Batı'nın arka bahçesi olmuştur. Petit ve Emberling, miras bağlantılarının Orta Doğu'da evrensel olarak iddia edilmese ya da sürdürülmese de genellikle Batı'da dile getirildiğini ifade etmektedir. Orta Doğu uygarlıklarının izleri büyük ölçüde Amerika Birleşik Devletleri, Avrupa ve kısmen de bölgedeki müzelerde sürülebilmektedir. Avrupa müzelerinde sergilenen Orta Doğu nesnelerinin geçmişi 16. yüzyılın nadire

4 Mark Garrison, "Antiquarism, Copying, Collecting," A Companion to the Archaeology of the Ancient Near East (Oxford: Blackwell Publishing, 2012), 27-47.

5 Claudia Suter, "Gudea of Lagash: Iconaclasm or Tooth of Time?" Iconaclasm and Text Destruction in the Ancient Near East and Beyond (Chicago: The Oriental Institute of Chicago McNaughton \& Gunn, Saline, Michigan, 2012), 57-88.

6 Pamela Erskine Loftus, "A Brief Look at the History of Museums in the Region and Wider Middle East," $2 \mathrm{~A}$ Architecture and Art Magazine 13 (2010), 18.

7 Suhail Bisharat, "Museums, Collections and Collecting in the Arab World," International Museum Managament and the Curatorship 4/3 (1985), 280.

8 Loftus, "A Brief Look at the History of Museums in the Region and Wider Middle East," 19.

9 Lucas Petit ve Geoff Emberling, Museums and the Ancient Middle East: Curatorial Practice and Audiences (New York: Routledge, 2018), 20. 
kabinelerine ve büyük saray koleksiyonlarına dayanmaktadır. Louvre ve British Müzesi geniş Orta Doğu koleksiyonlarına sahipken, Shaw, Osmanlı Müzeciliği ${ }^{10}$, Edhem ise, Modern Sanat Müzesi'nin Tasarımı: Müzecilik isimli kaynaklarda İstanbul'da açılan Müze-i Hümayun (İstanbul Arkeoloji Müzeleri) ile Osmanlıların kendi Orta Doğu koleksiyonlarını izleyiciyle buluşturduklarını belirtmektedir ${ }^{11}$.

Orta Doğu coğrafyasında Batılı örneklere benzeyen modern müzelerin ziyaretçiyle buluşmas1 19. yüzyılın son çeyreğine tarihlenmektedir. Lübnan'da 1868 'de Beyrut Amerikan Üniversitesi Müzesi açılmıştır. Lübnan Ulusal Müzesi'nin yapımına ise 1923 'te başlanmış ve müze 1942'de açılmıştır. Loftus, Erken Orta Doğu kökenli koleksiyonlar ve müzeler hakkında köklü geçmişe sahip iki ülke olan Misır (1880'ler) ve Irak'taki (1920'ler) ulusal müzelerde sergilenen eserlerin antik dönem koleksiyonları olduğundan söz etmektedir ${ }^{12}$. Orta Doğu coğrafyasında bulunmamakla birlikte kültürel olarak Arap ülkeleri arasında yer alan Fas'ta Dar Batha Müzesi ve Rabat'taki Ulusal Mücevher Müzesi 1910'da, Suriye'de Ulusal Müze 1919'da, Kudüs'te Fransız Arkeoloji Müzesi 1902'de, İslami Müze 1923'te, Afganistan'da ise Kabil Müzesi 1924'te açılmıştır. Bu müzelerde Batılı sınıflandırma sistemleri uygulanmıştır. Müzeler, batılı akademik disiplinlerin okullarına bağlı olarak yerel anlayışla değil, batı akademisinin anlayışına göre düzenlenmişlerdir. Batı tarzı Neoklasik tarzda inşa edilmiş yapılar içine yerleşen bu müzeler 1970'lere kadar benzer bir yaklaşımla yönetilmişlerdir ${ }^{13}$.

Orta Doğu'nun ikinci bölgesel kompleksi olan Irak, İran, Suudi Arabistan, Kuveyt, Birleşik Arap Emirlikleri (BAE), Umman ve Bahreyn'i içine alan Arap Körfezi'nde BAE ve Katar'ın başı çektiği coğrafyada kültürel miras ve müzecilik çalışmaları 1970’ten sonra hız kazanmıştır. 1960’tan önce Körfezin bedevi geleneği ve kültürü nedeniyle olası koleksiyonların kayıtlarını tutmak mümkün olmamıştır. 1970’ten sonra ise Bisharat'nn da belirttiği gibi Körfez müzeleri, Orta Doğu'da da istikrarın ödülleri ve birlik vitrinleri olarak ulusal kimliği inşa etmek için kurulmaya başlanmıştır ${ }^{14}$. Bugün Arap Körfezi, Batı'nın gelenek fikrine meydan okumaktadır. Geleneği bir zemin olarak kullanarak "geleneksel kültür tarafından şekillendirilen modern toplum» çağrışımıyla yüzünü geleceğe dönmüş ve ilerici bir yaklaşımla atılımlar yapar hale gelmiştir. Bisharat, BAE'nin ulusal kültür inşası sürecinde öne çıkan müzelerini şu şekilde sıralamaktadır: Fujairah Müzesi 1970’te, Dubai Müzesi ve Al-Ain Ulusal Müzesi ise 1971'de ziyaretçiyle buluşmuştur. Bugün adı Umman Miras Müzesi olan Umman Müzesi Muskat'ta 1974'te, Umman Ulusal Müzesi ise 1978'de ziyarete açılmıştır. Katar Ulusal Müzesi 1975 'te ziyaretçileriyle buluşmuştur. Kuveyt'in

10 Wendy Shaw, Osmanlı Müzeciliği (İstanbul: İletişim Yayınları, 2020), 45.

11 Halil Edhem, Modern Sanat Müzesi’nin Tasarımı: Müzecilik (İstanbul: İletişim Yayınları, 2019), 23.

12 Loftus, "A Brief Look at the History of Museums in the Region and Wider Middle East," 20.

13 Loftus, "A Brief Look at the History of Museums in the Region and Wider Middle East," 20.

14 Bisharat, "Museums, Collections and Collecting in the Arab World," 280. 
en önemli müzelerinden biri olan Tarık Sayid Rajab Müzesi 1980'de kurulmuştur. 1983'te Kuveyt Ulusal Müzesi, 1984'te Katar Folklor ve Sanat Müzesi, 1985'te Umman Doğa Tarihi Müzesi, 1987'de BAE'de Ras al-Khaimah Müzesi, 1988'de Bahreyn Ulusal Müzesi ve Katar Etnografya Müzesi hizmete girmiştir ${ }^{15}$.

1990'dan beri Körfez'de müze sayısı artmaya devam etmektedir. Bahreyn'de 1990 'da Beit al Kur'an İslam sanatlarına odaklanan çok amaçlı bir kültür merkezi olarak kurulmuştur. 1992'de Umman'da Fransız Müzesi ve 1999'da Suudi Arabistan Riyad'da Ulusal Müze ziyarete açılmıştır. BAE, Körfez'deki planlı dönüşüm döneminin en önemli örneğidir. Bu dönüşüm daha sonra diğer körfez ülkelerini de etkileyecek bir "ulusal kimlik oluşturma" dönemidir. Hacioğlu ve Saylan, BAE'nin, diğer Kuzey Afrika - Orta Doğu Körfez ülkeleriyle (Umman, Katar, Kuveyt vb.) petrole dayalı ekonomisini son yirmi yılda kalkınma politikaları doğrultusunda turizm sektörünü hareketlendirerek çekim merkezi haline gelmek amacıyla çeşitlendirmeye çalıştığını ifade etmektedir ${ }^{16}$. BAE'de kurulan ilk müzeler, tarih ve arkeoloji koleksiyonlarını geleneksel müzecilik yaklaşımı doğrultusunda korumayı ve ulus inşası sürecine katkı sağlamayı amaçlamıştır. Bouchenaki, son yirmi yılda bu iki müze yaklaşımının ötesinde çağdaş sanattan doğa tarihine, sinema tarihinden paraya kadar çeşitli koleksiyonlara sahip "yeni müzeler" ortaya çıktı̆̆ını ifade etmektedir ${ }^{17}$. Karadeniz, BAE müzelerine ilişkin şu şekilde bir kronoloji sunmaktadır ${ }^{18}$ : Al Ain Ulusal Müzesi, Al Muwaji Köşkü, Ajman Müzesi gibi ulusal kimliği öne çıkaran müzeler koleksiyonun kronolojik bir yaklaşımla sergilendiği örneklerdir. 1995'te açılan ve 2000'de yenilenerek ziyaretçiyle buluşan Dubai Müzesi, sergilediği etnografik koleksiyonu koruyarak 2006'dan itibaren video, dijital ve dokunmatik ekranlardan oluşan bir sergi tasarımı geliştirmiştir. Sharjah'da 1996'da kurulan İslam Uygarlıkları Müzesi halen bölgenin en büyük İslam Uygarlıkları müzelerinden biri olarak kabul görmektedir. 2005'ten sonra geçirdiği restorasyonla eğitim atölyesi, teknoloji kullanımına odaklanan sunumları ve uluslararası iş birlikleriyle gerçekleştirdiği geçici sergilerle öne çıkmaktadır. 2000'den sonra Dubai'de iş insanlarının ve sanatçıların kişisel koleksiyonlarını müze haline getirdikleri görülmektedir. Saruq Al-Hadid Arkeoloji Müzesi, Naif Kalesi Müzesi ve Şair Al Oqaili Müzesi, Para Müzesi, İnci Müzesi, Salsali Sanat Müzesi, Kahve Müzesi, Sinema Tarihi ve Hareketli İmajlar Müzesi ve Dubai Kadın Müzesi gibi örnekler aynı zamanda BAE’nin ilk özel müzeleri olarak da öne çıkmaktadır. Dubai'de irili ufaklı özel müzeler açıldıktan sonra müzecilik yaklaşımı, yerini popüler ve evrensel müzeler dalgasına bırakmıştır.

15 Bisharat, "Museums, Collections and Collecting in the Arab World," 281.

16 Necdet Hacıoğlu ve Uğur Saylan, “Arap Baharının Turizme Yansımaları: Arap Ülkeleri ve Türkiye,” Balıkesir Üniversitesi Sosyal Bilimler Enstitüsü Dergisi 17/32 (2014), 57.

17 Mounir Bouchenaki, "The Extraordinary Development of Museums in the Gulf States," Museum International 63/3-4 (2013), 97.

18 Ceren Karadeniz, "Birleşik Arap Emirlikleri’nde Kültürel Miras ve Müzeler,” Yedi: Sanat, Tasarım ve Bilim Dergisi 20 (2018), 139. 
Louvre Müzesi iş birliğiyle Abudhabi'de açılan Abudhabi Louvre bu uygulamaya örnek olarak gösterilebilir.

Tablo 1: Orta Doğu ve Arap Müzeleri Zaman Çizelgesi (Haz. Ceren Güneröz)

\begin{tabular}{|c|c|c|}
\hline Ülke & Müze & Kuruluş Yılı \\
\hline Fas & Dar Batha Müzesi & 1910 \\
\hline Fas & Rabat Ulusal Mücevher Müzesi & 1910 \\
\hline Suriye & Ulusal Müze & 1919 \\
\hline Kudüs & Fransız Arkeoloji Müzesi & 1910 \\
\hline Kudüs & İslami Müze & 1923 \\
\hline Afganistan & Kabil Müzesi & 1924 \\
\hline Birleşik Arap Emirlikleri & Fujairah Müzesi & 1970 \\
\hline Birleşik Arap Emirlikleri & Dubai Müzesi & 1971 \\
\hline Birleşik Arap Emirlikleri & Al Ain Müzesi & 1971 \\
\hline Birleşik Arap Emirlikleri & Ras al-Khaimah Müzesi & 1987 \\
\hline Birleşik Arap Emirlikleri & Dubai Müzesi & 1995 \\
\hline Umman & Umman Müzesi & 1974 \\
\hline Umman & Umman Ulusal Müzesi & 1978 \\
\hline Umman & Doğa Tarihi Müzesi & 1985 \\
\hline Umman & Fransız Müzesi & 1992 \\
\hline Katar & Katar Ulusal Müzesi & 1975,2019 \\
\hline Katar & Folklor ve Sanat Müzesi & 1984 \\
\hline Katar & Etnografya Müzesi & 1988 \\
\hline Kuveyt & Tarık Sayid Rajab Müzesi & 1980 \\
\hline Kuveyt & Kuveyt Ulusal Müzesi & 1983 \\
\hline Bahreyn & Bahreyn Ulusal Müzesi & 1988 \\
\hline Bahreyn & Beit al Kur'an Kültür Merkezi & 1990 \\
\hline Suudi Arabistan & Riyad Ulusal Müzesi & 1999 \\
\hline
\end{tabular}

2007'de temelleri atılan Louvre Abudhabi, “dünyaya açık bir ruha sahip”, hem temsil ettiği kültürler hem de ziyaretçi çeşitliliğiyle kültürlerarası diyaloğu geliştirmeyi hedefleyen bir müze olarak tanıtılmıştır. Mubarak ve Martinez, bölgede kendi kimliğini ve dinamiğini oluşturarak zaman ve mekân ile sınırlandırılamayacak evrensel bir misyonu temsil etmek amacıyla açılan Louvre Abudhabi'nin 21. yüzyılın en büyük güç gösterilerinden biri olduğunu ifade etmektedir ${ }^{19}$. Karadeniz'in belirttiğine göre, Fransız Müzeler Ajansı'nın danışmanlığında oluşturulan müzenin kuruluşu sırasında Müze d'Orsay, Pampidou Sanat Merkezi, Fransa Ulusal Kütüphanesi, Ulusal Asya Sanatları Müzesi, Versaille Müzesi ve Rodin Müzesi gibi kültür merkezlerinden 300 nesne ödünç alınmış; 600 nesne ise satın alma yoluyla, bağışla ve doğrudan Louvre Paris koleksiyonundan derlenerek müzeye kazandırılmıştır. 2017 yılında açılan ve 55 galeri ve 
23 sergi alanından oluşan müze, mimar Jean Nouvel'in tasarımıdır ve BAE'nin coğrafi özelliklerinden de esinlenerek çöl güneşini içeri alacak şekilde yapılandırılmıştır ${ }^{20}$. BAE'nin Abudhabi'deki Saadiyat Adası'nda Fransa, ABD ve İngiltere iş birlikleriyle açmayı planladığı yeni müzeler göz önünde bulundurulduğunda Küçük'ün belirttiği gibi, çölde bir sanat vahası mı yoksa distopik bir müzeler adası $\mathrm{m} 1$ olacağı belli olmayan bir proje olarak görülmektedir ve bu distopik adanın geleneksel ve yerel kodlarla hiçbir ortak noktası yoktur ${ }^{21}$. Kreps' in, vurguladığ gibi büyük ve ihtişamlı olan şey her zaman "iyi” olacak diye bir kural da yoktur. Önemli olan bulunduğu kültürü de yansitabilen bölgesel izleyiciye de "uygun müzeyi" kurmak ve müzenin ifade etmek istediğini kusursuz biçimde anlatmaktır. Bu doğrultuda Louvre Abudhabi dışında iki müzenin daha açılması planlanmaktadır. Guggenheim Müzesi'nin bir kolu olacak Abudhabi Guggenheim ve British Müzesi kontrolünde açllacak Şeyh Zayed Ulusal Müzesi BAE’nin miras sektörü atılımları içinde yer almaktadır. Guggenheim koleksiyonunun Orta Doğu'nun çağdaş sanat koleksiyonuna vurgu yapması; Zayed Ulusal Müzesi'nin ise, BAE'nin ulusal tarihine odaklanması beklenmektedir ${ }^{22}$.

Körfez'deki planlı dönüşüm ülkeleri arasında yer alan Katar'da kültürel miras ve müzeciliğe ilişkin ilk çalışmalar Al Thani ailesinin egemenliğiyle birlikte başlatılmış, 1975 'te Katar Ulusal Müzesi ziyarete açılmıştır. Müze, çölde yaşayan göçebe Bedevi kabilelerinin gündelik eşyalarını, inci avcılı̆̆ını, Bedevi kabilelerin fotoğraflarını ve sikke koleksiyonunu içermiştir. Karadeniz, Katar'da 2005 itibarıla müzecilik çalışmalarında artış yaşandığını belirtmektedir'23. 2005'te Katar Müzeler Birliği’nin kurulmasının ardından 2008'de ünlü mimar I. M. Pei'nin tasarladığı Katar İslam Sanatları Müzesi açılmıştır. 2010'da ise Mathaf: Arap Modern Sanat Müzesi açılarak modern sanat alanında önemli bir adım atılmıştır. Katar şehir merkezinde yer alan tarihi çarşı Souq Waqif aslına uygun biçimde restore edilmiş ve ulusal kültürün ayağa kaldırılması projesi hız kazanmışır. Katar Ulusal Müzesi Körfezdeki mimari zaferlerden biri olarak kabul edilmektedir. Ulusal Müze titanyum kaplama cephesiyle yeni müzelerin "nasıl görünmesi gerektiği" iddiasının önemli bir temsildir. Müze binası "çöl gülüne (Selenit)" atıf yapacak şekilde dış cephesini oluşturan 500 diskten oluşturulmuştur. Louvre Abudhabi'nin de mimarı olan J. Nouvelle, Katar'ın içerdiği zıt özellikleri sembol bir elementle anlatmayı amaçlamıştır. Çöl gülünün kristalize yapısı aynı zamanda geleceği temsil etmektedir ${ }^{24}$. Orta Doğunun siyasi çalkantıların ötesinde

20 Karadeniz, "Birleşik Arap Emirlikleri’nde Kültürel Miras ve Müzeler," 139.

21 Cihan Küçük, "Louvre Abudhabi Açıldı: Körfez'in Evrensel Müze Teşebbüsü,” E-skop Bülten (14 Ekim 2017), erişim 15 Ekim 2017, http://www.e-skop.com/skopbulten/louvre-abu-dhabi-acildi-korfezin-evrenselmuze-tesebbusu/3581\#_edn5

22 Christina Kreps, "Appropriate Museology in Theory and Practice," Museum Management and Curatorship 23 (2008), 40.

23 Ceren Karadeniz, "Katar'da Kültür, Miras ve Müze Çalışmaları," Süleyman Demirel Üniversitesi ART-E Güzel Sanatlar Fakültesi Dergisi 12/24 (2019), 733.

24 Karadeniz, "Katar'da Kültür, Miras ve Müze Çalışmaları," 735. 
zengin kültürel mirasını dünyanın gündemine taşıyacak müzelerle adından söz ettirmesi; tarih, arkeoloji ve halkbilim çalışmalarını ulusal kültür inşası amacıyla ülkesel bazda gündeme getirmesi dikkat çekici bir sürecin de başladığına işaret etmektedir.

\section{Ürdün'de Müzecilik Çalışmalarının Zaman Çizelgesi}

Sömürgecilik Ürdün'de de diğer Arap ülkelerinde olduğu gibi kalıcı bir iz ve sürdürülebilir bir miras bırakmıştır. Sömürge süreçlerinde arkeolojik kaynakların sağlanması, ulusal müzelerin kurulması ve çeşitlenmesi için geçmiş ve güncel yaklaşımlar tanımlanmış; miras alanında eğitim yaygınlaşmıştır. Müze türlerine, müze eğitimine ve deneysel arkeolojiye ilgi artmıştır. Bu bağlamda Ürdün devleti bir yandan mevcut müzeleri geliştirirken diğer yandan yeni ihtisas müzeleri kurma konusunda atılımlar gerçekleştirmiştir. Osmanlı Devleti'nin egemenliği döneminde Ürdün'ün taşınabilir kültürel miras varlıklarının gayri resmi yollarla ülke dışına çıkarılması veya bazı anlaşmalar doğrultusunda yabancı uzmanlara verilmesi ve 1967 yılından önce Filistin Arkeoloji Müzesi'ndeki (Rockefeller Müzesi) bazı eserlerin yurt dışına çıkarılması kültürel mirasın kaybedilmesine neden olmuş; Kafafi'ye göre, kaçakçılık yasalarla 2000'de engellenebilmiş ve mirasın yerinde sergilenebilmesi için yeni ve çağdaş müzelere ihtiyaç artmıştır25.

Kennedy ve Bewley ile Scheltema; Ürdün'ün çağlar boyu önemli uygarlıklara ev sahipliği yaptığını ve bu bağlamda Arap coğrafyasında değerli nesnelerin toplanması fikrinin İslam öncesi döneme kadar uzandığını ifade etmişlerdir ${ }^{26}$. Hitti, Mekke'de yer alan Kabe'nin çağlar boyu değerli dini nesnelerin toplandığı bir mekân olduğunu belirtmektedir ${ }^{27}$. İslâmiyetle birlikte maddi değere sahip nesneleri korumak için vakıfların kurulması mülkiyetin de korunmasını teşvik etmiş; kültür nesnelerinin himaye altına alınmasını sağlamıştır. Bununla birlikte el yazmaları, değerli kitaplar, dini nesneler, pişmiş toprak malzemeler vb. okullara ve camilere bağışlanmış ve bu ortamlarda koruma altına alınarak koleksiyonların oluşturulması sağlanmıştır. 16. yüzyıldan 20. yüzyılın başına kadar Ürdün ve diğer Arap ülkeleri, Osmanlı Devleti'nin kontrolü altındadır. Bu dönemde kişisel koleksiyonlar dışında Arap dünyasına ilişkin nesneler imparatorluğun başkenti İstanbul'da himaye edilmiştir. 19. yüzyılda Ürdün'de açılan müzelerde vakıflara ait koleksiyonlar ve kişisel koleksiyonlar sergilenmiş̧ir. Alawneh vd., 19. yüzyılda İslami el yazmalarının, tekstillerin, silah ve cam eserlerin Kahire'deki İslam Eserleri Müzesi’ne ve Kudüs’teki İslam Müzesi’ne götürüldüklerini ve oralarda sergilendiklerini ifade etmektedir ${ }^{28}$.

25 Zeidan Kafafi, "Who Owns the Past: Jordanian Archaeological Masterpieces at the International Museums," Studies in the History of Archaeology of Jordan XIII (2019), 639.

26 David Kennedy ve Robert Bewley, Ancient Jordan from the Air (London: The Council for British Research in the Levant, 2004), 128.

27 Philip K. Hitti, History of Arabs from the Earliest Times to Present (London: McMillan Press Ltd., 1974), 93.

28 Firas Alawneh, Raed Alghazawi ve Fadi Balaawi, "Culture Heritage and Idea of Jordan Museums," Asian Social Science 8/7 (2012) 106. 
19. yüzyılın başında Osmanlı İmparatorluğu Kuzey Afrika üzerindeki kontrolünü yitirmiştir. Hitti, 1798'de Napolyon Bonapart'ın Mısırı iş̧galinin aynı zamanda Kuzey Afrika'daki Arap ülkelerinde de koloni döneminin başlamasına neden olduğunu ifade etmektedir ${ }^{29}$. Ürdün dahil Fas, Tunus, Cezayir ve Libya gibi ülkelerdeki müzecilik bu dönemin kolonist çalışmalarının sonucunda başlamıştır. Kutsal toprakların statüsü nedeniyle Filistin ve Ürdün kültürel miras açısından özel ilgi görmüştür. Hristiyan misyonerler, çeşitli tarikatların mensupları ve dini nesnelere ilgi duyan koleksiyonerler bu bölgede kazılar yaparak Kutsal toprakların kültürel mirasının korunmasında ve tanınmasında etkili olmuşlardır. Sadeq, Ürdün'e 1333'te Fransiskanların, 1878'de Beyaz Rahiplerin, 1878'de Beytüllahim'e gelen Betharamlı Rahiplerin ve 1891'de bölgede kurulan Arkeoloji kütüphanesinin bölgede yürütülen kazılarda etkin rol oynadıklarını ve 18. ve 19. yüzyıllarda Almanların da bölgede arkeolojik keşifler yaptığını belirtmektedir ${ }^{30}$.

Ürdün ve Lübnan'1 içine alan Levant Bölgesi’nde ve Doğu Akdeniz`de turizmin gelişmesi, 19. yüzyılın ikinci yarısında İngiliz Thomas Cook turizm firmasının etkinlikleriyle gerçekleşmiştir ${ }^{31}$. Avrupa'dan başlayan antikite yolculukları, Mısırıın eski anıtlarını, Nil Deltası'nı, Filistin'deki kutsal yerleri, Beyrut, Kudüs ve Şam gibi büyük şehirlerdeki başlıca antik sit alanlarını kapsamıştır. Baalbek’teki Jüpiter Tapınağ1, Kubbet-üs-Sahra ve Kudüs’teki Kutsal Kabir, Şam'daki Emevi Camii, Palmira harabeleri ve Petra şehri en popüler turistik alanlardır. 20. yüzyılın ilk yarısında bölgedeki manda yönetimiyle Ürdün'ün klasik, dini ve antik yapıları miras kapsamında değerlendirilmeye başlanmıştır.

1865 'te, bir grup Batılı akademisyen ve din adamı tarafından Filistin Keşif Fonu (PEF) kurulmuştur. PEF'in amacı, Filistin ve Ürdün bölgesinde arkeoloji ve tarih, gelenek ve görenek, kültür, topografya, jeoloji, doğa bilimleri ve din konulu araştırmaları teşvik etmektir ${ }^{32}$. 1870'te Amerikan Filistin Keşif Topluluğu (APES) ve Ürdün İngiliz yönetimindeyken 1920'de Antik Eserler Birimi kurulmuştur. Sadeq, 1927 'de 19. ve 20. yüzyılda gün yüzüne çıkarılan eserlerin sergilenmesi için bir arkeoloji müzesi oluşturulduğunu belirtmektedir ${ }^{33}$. John D. Rockefeller Jr.'ın girişimleriyle müze yeni bir binaya taşınmıştır. 1938'de Filistin Arkeoloji Müzesi ziyarete açılmıştır ${ }^{34}$. 1923 'te Ürdün'de Antik Eserler Birimi kurulmuştur. Alawneh vd. birimin görevinin Ürdün'deki antik sit alanlarının ve eserlerin korunmasını ve

29 Hitti, History of Arabs from the Earliest Times to Present, 721.

30 Mouin Sadeq, “Archaeological Museums in Palestine: Reality and Prospective," Proceedings of the Encounter Museums, Civilization and Development (Paris: International Council of Museums, 1994), $287-291$.

31 Robert F. Hunter, "The Thomas Cook Archives for the Study of Tourism in the North Africa and the Middle East," Middle East Association Bulletin 26/2 (2003), 157.

32 "Palestine Expolariton Fund," erişim 30 Ekim 2020, https://www.pef.org.uk/

33 Sadeq, “Archaeological Museums in Palestine: Reality and Prospective," 290-291.

34 Carol Malt, Women's Voices in Middle East Museums: Case Studies in Jordan (Gender, Culture and Politics in the Middle East (New York: Syracuse Unversity Press, 2005), 85. 
sürdürülebilir hale gelmesini sağlamak olduğunu belirtmiştir. Birimin devletin arkeoloji politikasını yürütmek, Krallıktaki antikaların, antik sit alanlarının ve eserlerin korunma, bakım, onarım ve muhafazası ile çevrelerinin güzelleştirilmesi ve teşhir stratejilerinin belirlenmesi üzerine çalışmalar yürütmek, Krallıkta farklı miras enstitülerinin kurulmasını sağlamak, müzeler için teknik ve mali destek sağlamak, kültürel mirasa hizmet eden müzecilik gruplarına destek vermek gibi amaçlarla çalışmalarını sürdürdüğü söylenebilir. 1925 'te antik eserlerin korunmasına ilişkin bir kanun çıkarılmış ve 2004'te yenilenmiştir ${ }^{35}$.

Ürdün 1945 ’te, Arap Birliği Eğitim, Bilim ve Kültür Kuruluşu (ALESCO)'na katılmıştır. Malt, 1948 'den itibaren arkeolojik kazıların Ürdünlü bilim insanları tarafından yürütülmeye başlandığını ifade etmektedir ${ }^{36}$. İsrail ile yapılan 1967 savaşının sonucu olarak, Ürdün Batı Şeriaıyı ve beraberinde yalnızca tarım arazilerini ve fabrikalarını değil aynı zamanda dini, arkeolojik ve turistik alanlarının bir bölümünü de kaybetmiştir. Böylece çoğu yabancı araştırma kurumu -İngiliz Arkeoloji Enstitüsü, Amerikan Doğu Araştırmaları Merkezi, Alman Evanjelik Kutsal Topraklar Enstitüsü ve Fransız Arkeoloji Enstitüsü- Amman〉da yeni şubelere transfer edilmiştir. Ürdün'ün ilk arkeoloji müzesi 1923'te Artemis Tapınağı'nın bir bölümünde İngiliz yönetimi altında kurulmuştur. Bu müze, halka açık nesnelerin sergilendiği bir müze kurmak ya da eğitsel bir alan oluşturmak yerine eserlerin saklandığ 1 bir depo yapı olarak betimlenmektedir. Malt, Ürdün'de ilk kurulan depo müzelerde Arap kültüründen eser olmadığını, Arapların kendi özlerini ve özgünlüklerini ararken sömürgeciliğin de etkisiyle kültürel kimlik karmaşası yaşadıklarını ve geçmişiyle özdeşleşmeyen biçimlerde kültürel temsil arayışına girdiklerini vurgulamıştı ${ }^{37}$. Depo görünümünde olsalar da ilk müzeler ve arkeolojik çalışmalar Arapların miraslarını tanımalarına katkıda bulunmuştur. Farkındalığın artmasına rağmen 1923'ten sonraki otuz yıl boyunca, farklı nedenlerle Ürdün'de yeni müze kurulmamıştır. Alawneh vd.'ye göre, Genç Krallık müze vb. kültür kurumları kurmaktan ziyade ülkeyi inşa etmeye odaklanmış ve politik, ekonomik ve sosyal durumlardaki istikrarsızlı̆̆ 1 düzeltmekle uğraşmıştır. Ülkede yetişmiş arkeolog ve müze bilimci eksikliği ve yabancı arkeologların ve miras kurumlarının çalışmalarını Filistin'e yoğunlaştırmaları Ürdün'de müzecilik çalışmalarını geciktirmiştir ${ }^{38}$.

Alshishani, arkeolojik alan müzeleri üzerine gerçekleştirdiği yüksek lisans tezinde, Ürdün Arkeoloji Müzesi'nin inşası 1949'da Amman Kalesi’nde tamamlandığını ve müzenin 1951 'de halka açıldığını belirtmektedir ${ }^{39}$. Müzenin amacı Ürdün'ün

35 Alawneh, Alghazawi ve Balaawi, "Culture Heritage and Idea of Jordan Museums," 108.

36 Malt, Women's Voices in Middle East Museums: Case Studies in Jordan, 88.

37 Malt, Women's Voices in Middle East Museums: Case Studies in Jordan, 89.

38 Alawneh, Alghazawi ve Balaawi, "Culture Heritage and Idea of Jordan Museums," 108.

39 Kamal Alshishani "Arkeolojik Alan Müzeleri Üzerine bir İnceleme: İstanbul Arkeoloji Müzesi ve Ürdün Arkeoloji Müzesi Örneği,” (Yüksek Lisans Tezi, İstanbul Üniversitesi, 2018), 130. 
arkeolojik mirasını vurgulamaktır ve bu müze Ürdün Arkeoloji Müzesi, Turizm Bakanlığı ve Ürdün Antik Eserler Birimi tarafindan desteklenmektedir. Müzenin etkinlikleri Arkeoloji ve Eski Eserler Birimi ve yabancı misyonlarla kazı çalışmalarına katılım ile sınırlı olmuştur. Müze hem ülke içinde hem de Belçika, Fransa ve Almanya'da geçici sergiler düzenlenmiştir. Müze, laboratuvar, restorasyon atölyesi, kütüphane ve eğitim salonu gibi bölümlerden yoksundur. 1951'den sonra Doğu ve Batı Şeria'nın birleşmesiyle ekonomik ve eğitsel alt yapının oluşturulması amacıyla müzecilik etkinlikleri bir süre daha ertelenmiştir. Batı Şeria dini ve arkeolojik bölgeler bakımından daha zengin olduğu için Ürdün, Doğu Bölgesi'nde yeni müzeler kurma çabasına girmemiştir. Ürdün'ün 1954'te UNESCO'ya katılması ve Lahey Sözleşmesi'ni imzalaması müzecilik etkinliklerini tekrar gündeme getirmiştir.

Abu-Khafajah vd., Ürdün'de arkeolojik sit alanlarının yerel makamlar ve paydaşlar tarafından yönetimi süreçlerinde her zaman yukarıdan aşağıya bir yaklaşım benimsendiğinden söz etmişlerdir. Bu nedenle, yerel topluluklar yabancılaştırılmış; antik alanların yakınlarında yaşayanlar pasif topluluklar haline gelmişlerdir. Yerel halk, bu alanların korunmasında müttefik olarak değil bizzat alanlara zarar veren bir tehdit olarak görülmüsstür ${ }^{40}$. Ajaj, Ürdün'de 1923 'ten sonra özellikle otuz y1l boyunca bir çağdaş müze oluşturulamamasını üç nedene bağlamaktadır: Krallığın genç olması ve hükümetin kültür kurumları kurmaktan ziyade ülkeyi inşa etmeye odaklanmış olması; politik, ekonomik ve sosyal durumlarda istikrarsızlık ve yetişmiş arkeolog ve müzelerin toplumsal gelişmedeki rolü konusunda farkındalık eksikliğidir. Yabanc1 arkeologların Ürdün'den ziyade Filistin'de yoğunlaşan çalışmaları ve yerel halkın konuya ilgi duymamas da bu nedenlere eklenebilir ${ }^{41}$.

Ürdün'deki müzelerin çoğu arkeoloji müzesidir. Alshishani’ye göre, bunun nedeni, ülkedeki arkeolojik alanların çokluğu ve kazıların sayısı ve kapsamının fazla olmasıdır. Ürdün'de kazı sayılarının ve kapasitelerinin artması kazılardan elde edilecek eserlerin sağlıkı koşullarda korunması, bakım onarımlarının yapılması ve sergilenmesi gibi ihtiyaçları da doğurmaktadır. Ürdün'deki bazı arkeolojik kazılar Ürdün üniversiteleri ve Antik Eserler Birimi (DOA) tarafından yapılmış olsa da çoğu halen yabancı kuruluşlar tarafından yürütülmektedir ${ }^{42}$. Ülkede 18 arkeoloji müzesi vardır. Diğerleri ise, araştırma ve öğretime adanmış üniversite müzeleridir. Ülkedeki ilk arkeolojik sergileme yabancı arkeologlar tarafindan 1920'lerin sonunda Antik Yunan ve Roma kenti Jerash'ta yapılmıştır. 1951'de kurulan Ürdün Arkeoloji Müzesi aynı zamanda Ürdün Antik

40 Shatha Abu-Khafajah; Rama al Rabady ve Saheher Rababeh. "Urban Heritage Sapace Under Neoliberal Development: A Tale of Jordanian Plaza, ” International Journal of Heritage Studies 21 (2015), 451.

41 Ahmad M. Ajaj "The Historical Development of University Museums in Jordan (1962-2006): Objectives and Perspectives Case Studies of Archaeology Museums at the Jordan and Yarmouk Universities," (Dissertation of Doctor of Philosophy, University of Leicester, 2007), 67.

42 Alshishani “Arkeolojik Alan Müzeleri Üzerine bir İnceleme: İstanbul Arkeoloji Müzesi ve Ürdün Arkeoloji Müzesi Örneği,” 119. 
Eserler Birimi'nin de yönetim merkezi olarak kullanılmıştır. Bununla birlikte müze bağımsız bir ulusun dekolonizasyon hareketinin önemli bir sembolü olarak ülkenin ilk ulusal müzesi olarak kabul görmüştür ${ }^{43}$. 1962'de Ürdün'deki ilk ulusal üniversite olan Ürdün Üniversitesi’nin kurulması arkeoloji ve müzecilik etkinliklerinin akademik olarak yürütüleceği bir ortamı sunmuştur. Üniversiteyle birlikte aynı zamanda kampüste bir arkeoloji müzesi oluşturulmuştur. Bu gelişme üniversitenin ülkede müze kurulması sürecinde önemli bir rol oynadığını göstermektedir.

1951'den bu yana 12 arkeoloji müzesi daha hizmete açılmıştır. 1967 Arap-İsrail Savaşı öncesi DOA, Petra ve İbrid'de iki şube açmış, ardından Petra Arkeoloji Müzesi kurulmuştur. 1966 yılında ise İrbid Arkeoloji Müzesi ziyaretçileriyle buluşmuştur. 1964 ve 1965 'te Jerash ve Kerak Arkeoloji Müzeleri ziyarete açılmıştır. 1966 ve 1967'de ise Nablus ve Hebron Müzeleri ziyarete açılmıştır. 1966'da yılında DOA, Kudüs'te bir folklor müzesi kurmayı istemişse de savaş nedeniyle bu mümkün olmamıştır. Ajaj, 1971'de DOA'nın bu fikri Amman'da yeniden gündeme getirdiğini ve Ürdün Miras Kulübü tarafından Popüler Gelenekler Müzesi'nin ziyarete açıldığını ifade etmektedir. Müze Doğu ve Batı Şeria bölgelerinin geleneksel giysilerini, takılarını, dekoratif malzemelerini ve geleneksel dokumalarını içermiştir. 1975'te aynı yapı bünyesinde folklor müzesi açılmıştır. 1974'te Madaba'da Bizans mozaiklerine ev sahipliği yapan yapılar DOA tarafından bir müze kompleksine dönüştürülmüştür ${ }^{44}$.

DOA, 1974 ve 1975'teki girişimleriyle Kültür Varlıklarının Yasadışı İthalat, İhraç ve Mülkiyet Transferinin Yasaklanması ve Önlenmesi Yollarına İlişkin UNESCO Sözleşmesi'ni imzalamıştır. 1970'lerde arkeoloji müzeleri dışında farklı çeşitlilikte müzeler açılmıştır. Örneğin Ürdün Silahlı Kuvvetleri, Şehitler Müzesi'ni kurarken, Posta ve İletişim Bakanlığı bir filateli müzesi kurmuştur. Ürdün Üniversitesi yeni fakülteler açmış ve Biyolojik Bilimler Bölümü Hayvan Müzesi, Akabe Akvaryumu ve Kızıldeniz Deniz Bilimleri İstasyonu'nu kurmuştur. Fen Fakültesi bünyesinde ise, Bahçe Bitkileri ve Bitki Bölümü’nde bir Böcek Müzesi ve Ziraat Müzesi ziyaretçiyle buluşmuştur. 1970’ten itibaren Ürdün DOA sadece Ürdün'de değil, BAE ve Kuveyt gibi diğer Arap ülkelerinde de arkeoloji müzeleri kurulması konusunda görev üstlenmiş; bu müzeler için koleksiyon oluşturmuştur. DOA İngiltere, Fransa, ABD ve Almanya gibi ülkelerdeki müzelere de ödünç eser vermiştir ${ }^{45}$. 1980'ler, ekonomik büyüme açısından yetmişli yılların bir uzantısı olarak kabul edilebilir ve bu dönemde hem siyasi hem de ekonomik gelişmelerin müzecilik alanına da yansıdığı anlaşılmaktadır. 1980'de DOA, Kerak Arkeoloji Müzesi'ni yeniden ziyarete açmaya karar vermiştir.

43 Patrick J. Boylan, "Museums and Cultural Identity," Museum International 90/10 (1990), 31.

44 Ajaj, "The Historical Development of University Museums in Jordan (1962-2006): Objectives and Perspectives Case Studies of Archaeology Museums at the Jordan and Yarmouk Universities," 70.

45 "DOA, Departmet of Archaeology Brief History," erişim 13 Aralık 2020, https://doa.gov.jo/brief-historyar. aspx 
1983 ’te Al-Salt Arkeoloji Müzesi, kentin 30 km kuzeybatısındaki aynı adı taşıyan şehirde kurulmuştur. Müze, Amman, Al-Salt ve Al-Balqa bölgesinde yürütülen kazılarda elde edilen malzemeleri sergilemektedir. 1987'de Al-Salt Folklor Müzesi açılmıştır. DOA, aynı yıl Alman Protestan Arkeoloji Enstitüsü ile iş birliği yaparak Amman'ın kuzeyindeki Umm Qais'ta bir arkeoloji müzesini ziyarete açmıştır. DOA farklı kurum ve kuruluşlara da müze kurma konusunda destek vermektedir. Ürdün Merkez Bankası bünyesinde bir Nümizmatik Müzesi kurulmuştur. Müze, MÖ 3. yüzyıldan Ürdün Haşemi Krallığı Dönemine kadar farklı tarihlerde edinilmiş antik paraları sergilemektedir. DOA'nın bu çalışmaları Ürdün Antik Eserler Kanununda belirlenen "DOA, tarihi, sanatsal ve popüler müzeler dahil olmak üzere, Krallıktaki hükümet faaliyetleri ile ilgili müzelerin kurulmasına ve çalışmalarına yardım edecektir" maddesiyle ilişkilendirilebilir ${ }^{46}$.

1980’de Ürdün Üniversitesi Sosyoloji Bölümü tarafindan bir folklor müzesi açılmıştır. Bedevi yaşamın ayrıntılarına ilişkin kesitler sunan müze aynı zamanda Ürdün toplumunun köy yaşantısına ilişkin etnografik malzemeleri sergilemek üzere kurulmuştur. 1984 'te Yarmouk Üniversitesi benzer bir müze kurmuş ve müzede Ürdün'ün etnografik mirasını somut ve somut olmayan bağlamlarla ele almıştır. 1987'de DOA, Chicago Üniversitesi Oryantal Enstitüsü iş birliğiyle Akabe ve Kızıl Deniz kıyılarında kazı çalışmalarına başlamıştır. Bu çalışmalarda ele geçen çok sayida nesne Yarmouk Üniversitesi'nde sergilenmektedir. Bu nesneler zamanla gezici sergilerle farklı şehirlere götürülmüştür. Dolayısıyla 1990'da Akabe'de bir arkeoloji müzesi kurma fikri gündeme gelmiştir. 1990'dan itibaren, DOA ve bir özel sektör kuruluşu olan Arkeoloji Dostları (Friends of Archaeology) Sınırları Olmayan Müze (Museum with no Frontiers) isimli uluslararası projeye katılmıştır ${ }^{47}$. Proje, Avrupa Komisyonu tarafindan desteklenen ve en az on beş Akdeniz ülkesi arasındaki kültürel ilişkileri geliştirmeyi hedefleyen bir sanal müze uygulamasıdır. Müze, İslam sanatı eserlerini, mimari unsurlarını ve benzer malzemeleri çevrim içi platformda oluşturulan geniş bir ulus ötesi müze çatısında arkeolojik bağlamda sunmaktadır. Çevrim içi müze hem Avrupa'nın paylaşılan kültürel mirası hakkında bilgi edinme ve bunlardan yararlanma firsatı sağlamakta hem de Kuzey Afrika ve Orta Doğu'nun kültürel mirasına yeni bir bakış açısı getirmektedir. Ürdün'den otuz beş anıt ve sit alanı projede yer almış; Emevî, Erken Abbasi, Eyyubi, Memluk ve Osmanlı dönemlerine bağlı sit alanları ve yapılar proje veri tabanına dâhil edilmiştir.

1990'dan itibaren ülkenin kuzeyinde Ajlun Arkeoloji Müzesi ve güneyinde ise Mafraq Arkeoloji Müzesi açılmıştır. Aynı süreçte Ürdün Bilim ve Teknoloji Üniversitesi bünyesinde patoloji, tıbbi bitkiler ve anatomi müzeleri oluşturulmuştur.

46 “Law of Antiquties,” erişim 1 Aralık 2020, https://www.unodc.org/res/cld/document/law-of-antiquities_html/ Law_of_Antiquities-1-_jordan.pdf

47 “Museums with No Frontiers,” erişim 20 Aralık 2020, http://www.museumwnf.org/ 
Aynı yıllarda Amman'da çağdaş sanat galerilerinin açıldığı izlenmiştir. Ajaj, 1990'lar boyunca Ürdün'de 25 müze açıldığını belirtmektedir ${ }^{48}$. Ancak Malt, bu müzelerin eğitsel ya da diğer toplumsal işlevlere odaklanmadıklarını, daha çok nesneler için depo görevi gördüklerini ifade etmektedir ${ }^{49}$. 1990'ların sonlarında Amman'da Çocuk Müzesi ve Polis Müzesi ziyarete açılmıştır.

Tablo 2: Ürdün'deki Müzelerin Zaman Çizelgesi (Haz. Ceren Güneröz)

\begin{tabular}{|c|c|c|}
\hline Müze & Şehir & Kuruluş Yılı \\
\hline Jerash Arkeoloji Müzesi & Jerash & 1923 \\
\hline Ürdün Arkeoloji Müzesi & Amman & 1951 \\
\hline Arkeoloji Müzesi & Amman & 1962 \\
\hline Petra Arkeoloji Müzesi & Petra & 1963 \\
\hline Irdib Arkeoloji & Irdib & 1966 \\
\hline Mazar Müzesi & Mazar & 1968 \\
\hline Popüler Kültür Müzesi & Amman & 1971 \\
\hline Hayvan Müzesi & Amman & 1971 \\
\hline Intercontinental Oteli Galerisi & Amman & 1972 \\
\hline Madaba Arkeoloji Müzesi & Madaba & 1974 \\
\hline Madaba Folklor Müzesi & Madaba & 1974 \\
\hline Aqaba Akvaryumu ve Deniz Bilimleri İstasyonu & Aqaba & 1974 \\
\hline Folklor Müzesi & Amman & 1975 \\
\hline Böcek Müzesi & Amman & 1976 \\
\hline Şehitlik ve Anı Müzesi & Amman & 1977 \\
\hline Plastik Sanat ve Plastik Sanatçılar Birliği Galerisi & Amman & 1978 \\
\hline Ürdün Posta Müzesi & Amman & 1979 \\
\hline Ürdün Ulusal Güzel Sanatlar Galerisi & Amman & 1980 \\
\hline Folklor Müzesi & Amman & 1980 \\
\hline Kerak Arkeoloji Müzesi & Amman & 1980 \\
\hline Ürdün Doğa Tarihi Müzesi & Irbid & 1980 \\
\hline Tıp Tarihi Müzesi & Amman & 1980 \\
\hline Kraliyet Kültür Merkezi & Amman & 1980 \\
\hline Botanik Müzesi & Amman & 1982 \\
\hline Al Salt Arkeoloji Müzesi & Salt & 1982 \\
\hline Ürdün Miras Müzesi & İrbid & 1984 \\
\hline Çocukların Miras ve Bilim Müzesi & Amman & 1985 \\
\hline Salt Folklor Müzesi & Salt & 1987 \\
\hline Umm Qais Arkeoloji Müzesi & Irbid & 1987 \\
\hline Nümizmatik Müzesi & Amman & 1987 \\
\hline Mu'tah Üniversite Müzesi & Mu'tah & 1989 \\
\hline
\end{tabular}

48 Ajaj, "The Historical Development of University Museums in Jordan (1962-2006): Objectives and Perspectives Case Studies of Archaeology Museums at the Jordan and Yarmouk Universities," 80.

49 Malt, Women's Voices in Middle East Museums: Case Studies in Jordan, 89. 


\begin{tabular}{|c|c|c|}
\hline Jeoloji Müzesi & Amman & 1989 \\
\hline Petra Forum Müzesi & Musa Vadisi & 1990 \\
\hline Aqaba Arkeoloji Müzesi & Aqaba & 1990 \\
\hline Sheriff Hussein Bin Ali Müzesi & Aqaba & 1990 \\
\hline Patoloji Müzesi & Rambtha & 1990 \\
\hline Tıbbı Bitkiler Müzesi & Rambtha & 1992 \\
\hline Ajlun Kalesi Müzesi & Ajlun & 1993 \\
\hline Mafraq Arkeoloji Müzesi & Mafraq & 1993 \\
\hline Darat al Fünun & Amman & 1993 \\
\hline Fuheis Ortodoks Müzesi & Fuheis & 1993 \\
\hline Petra Nebati Müzesi & Petra & 1994 \\
\hline Anatomi Müzesi & Rambtha & 1994 \\
\hline Semerkand Müzesi & Mafraq & 1995 \\
\hline Sinırları Olmayan Müze & Amman & 1995 \\
\hline Şehir Galerisi & Amman & 1995 \\
\hline Sanatçılar Birliği Galerisi & Amman & 1995 \\
\hline İslam Müzesi & Amman & 1996 \\
\hline Kral 1. Abdullah Müzesi & Ma'an & 1996 \\
\hline Okul Kitapları Müzesi & Salt & 1997 \\
\hline Prenses Fakhr An-Nisa Zeid Galerisi & Amman & 1997 \\
\hline Politik Tarih Müzesi & Amman & 1998 \\
\hline Ürdün Ulusal Bankası Para Müzesi & Amman & 1999 \\
\hline Hicaz Demiryolu Müzesi & Amman & 1999 \\
\hline Abu Obadiah Islam Müzesi & Ürdün Vadisi & 1999 \\
\hline Sheriff Hussein Bin Ali Müzesi & Amman & 1999 \\
\hline Nebo Dağı Müzesi & Madaba & 1999 \\
\hline Kraliyet Arabaları Müzesi & Amman & 2002 \\
\hline Ürdün Ulusal Müzesi & Amman & $2002-2014$ \\
\hline Ölü Deniz Panorama Müzesi & Ürdün Vadisi & 2006 \\
\hline Vaftiz Müzesi & Ürdün Vadisi & 2006 \\
\hline Çocuk Müzesi & Amman & 2007 \\
\hline Dar A s-Saraia Müzesi & Irbid & 2007 \\
\hline Tank Müzesi & Amman & 2007 \\
\hline Fidan Müzesi & Vadi Arabah & 2008 \\
\hline Tarihi Salt Müzesi & Salt & 2010 \\
\hline Polis Müzesi & Salt & 2010 \\
\hline
\end{tabular}

Ürdün Müzesi, Batılı kent müzesi örneklerini anımsatan ve etkileșimli sergileriyle Ürdün tarihini orijinal nesnelerle anlatmayı hedefleyen çağdaş bir müze olarak dikkat çekmektedir. Müzenin arkeolojik geçmişini anlatan giriş katı 1001 Buluş isimli etkileşimli bilim sergisine açılmakta ve İslam bilim tarihini deneysel müze 
yaklaşımıyla izleyicisine sunmaktadır (G.1-G.6). Ürdün Çocuk Müzesi ise, eğitim odağında hizmet vermeyi amaçlayan bir müze olarak öne çıkmıştır. Müze, Kraliçe Rania Al-Abdullah tarafından 2007'de başlatılan, kâr amacı gütmeyen bir eğitim kurumudur. Müzede 180 'den fazla etkileşimli serginin yanı sıra kütüphane, sanat stüdyosu, laboratuvar ve gizli bahçeyi içeren eğitim tesisleri yer almaktadır. Müze, çocuk müzelerinin genel felsefesini kabul ederek öğrenmeyi herkes için keyifli hale getirmeyi planlayarak yerel ve bölgesel olarak geniş kitlelere ulaşmayı hedeflemektedir. Müzenin dokunmalı (hands-on) etkinlikleri sanat, uzay, biyoçeşitlilik ve bilim konularına odaklanmıştır. Çocuk Müzesi 2008'de “Herkes için Müze Girişimi” "ni başlatmış; devlet okullarındaki öğrencilere müzeyi ücretsiz hale getirmeyi ve dezavantajlı gruplara ulaşmayı amaçlamıştır. Bu kapsamda gezici bir müze oluşturulmuş, lojistik ve ekonomik nedenlerle müzeyi ziyaret edemeyen bireylerle iletişim kurulmuştur. Gezici müze hastanelere, mülteci kamplarına ve dezavantajlı bölgelere erişim sağlamıştır.

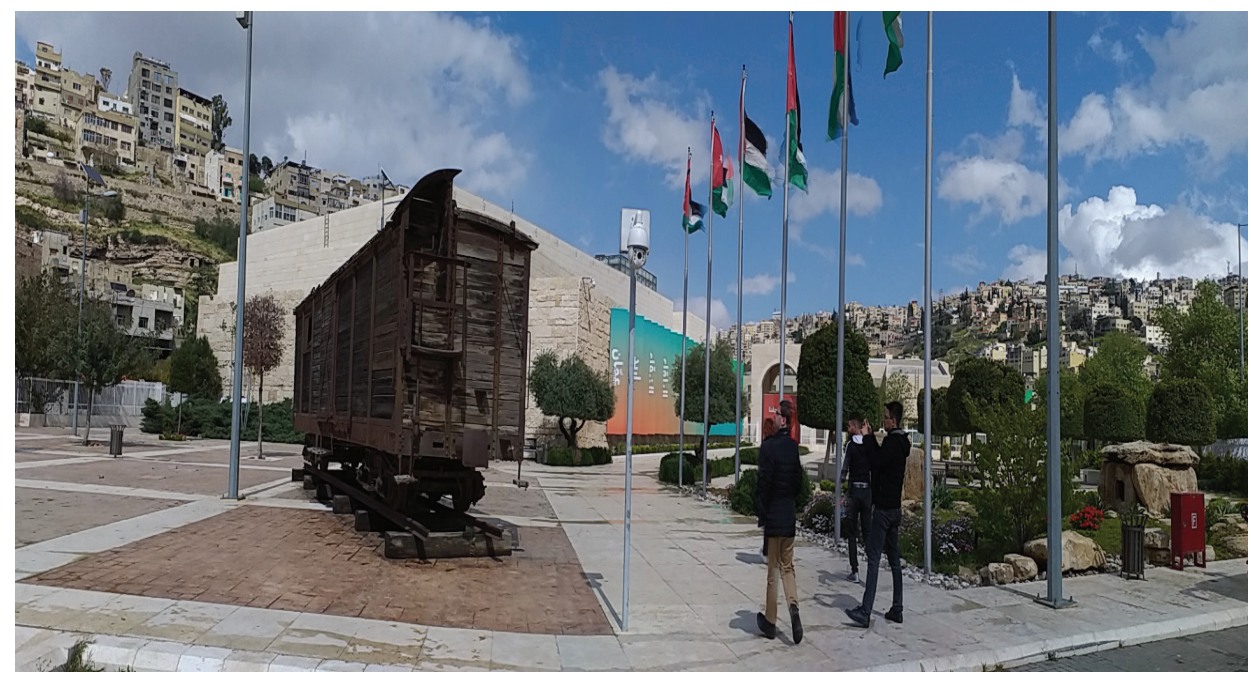

G. 1: Ürdün Müzesi genel görünüm (Ceren Güneröz, 2019) 


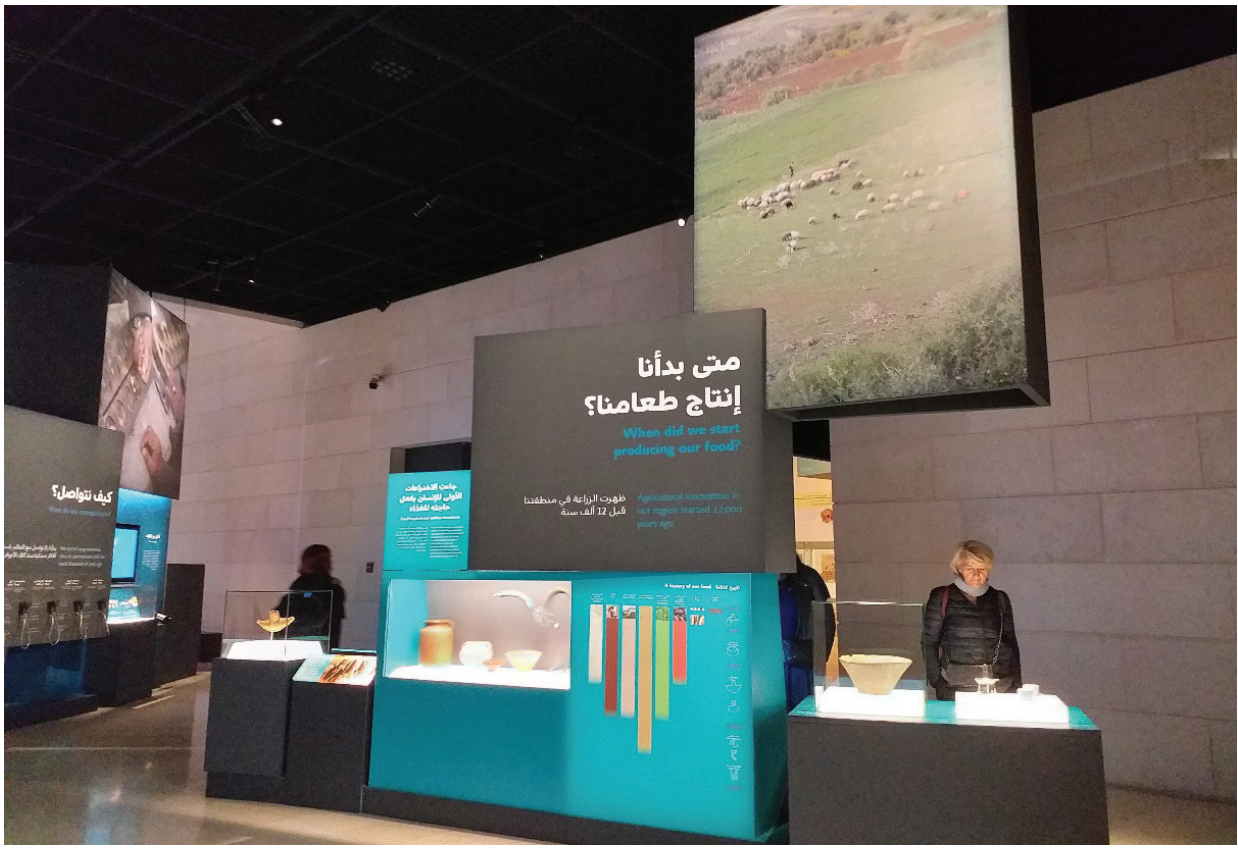

G. 2: Ürdün Müzesi ana galeri genel görünüm (Ceren Güneröz, 2019)

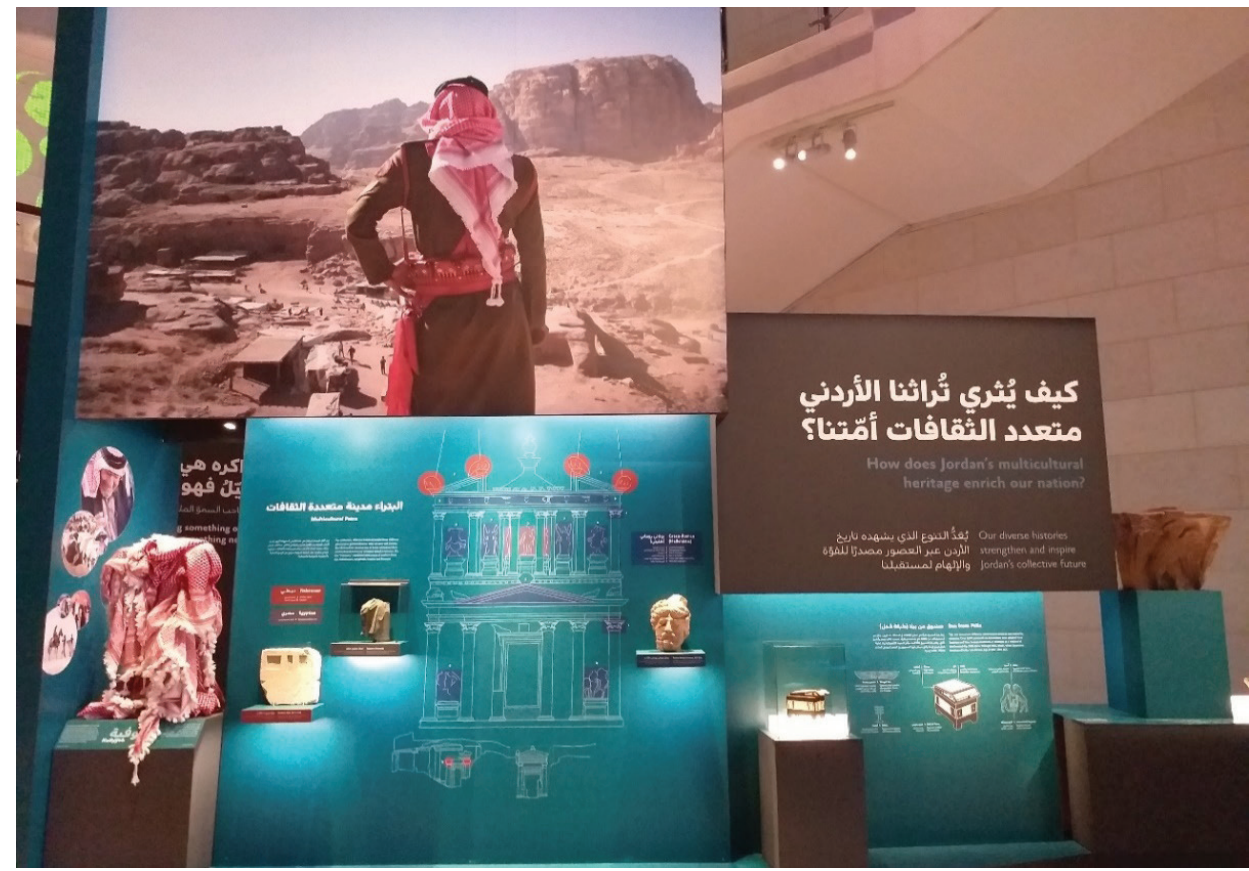

G. 3: Ürdün Müzesi ana galeri genel görünüm (Ceren Güneröz, 2019) 


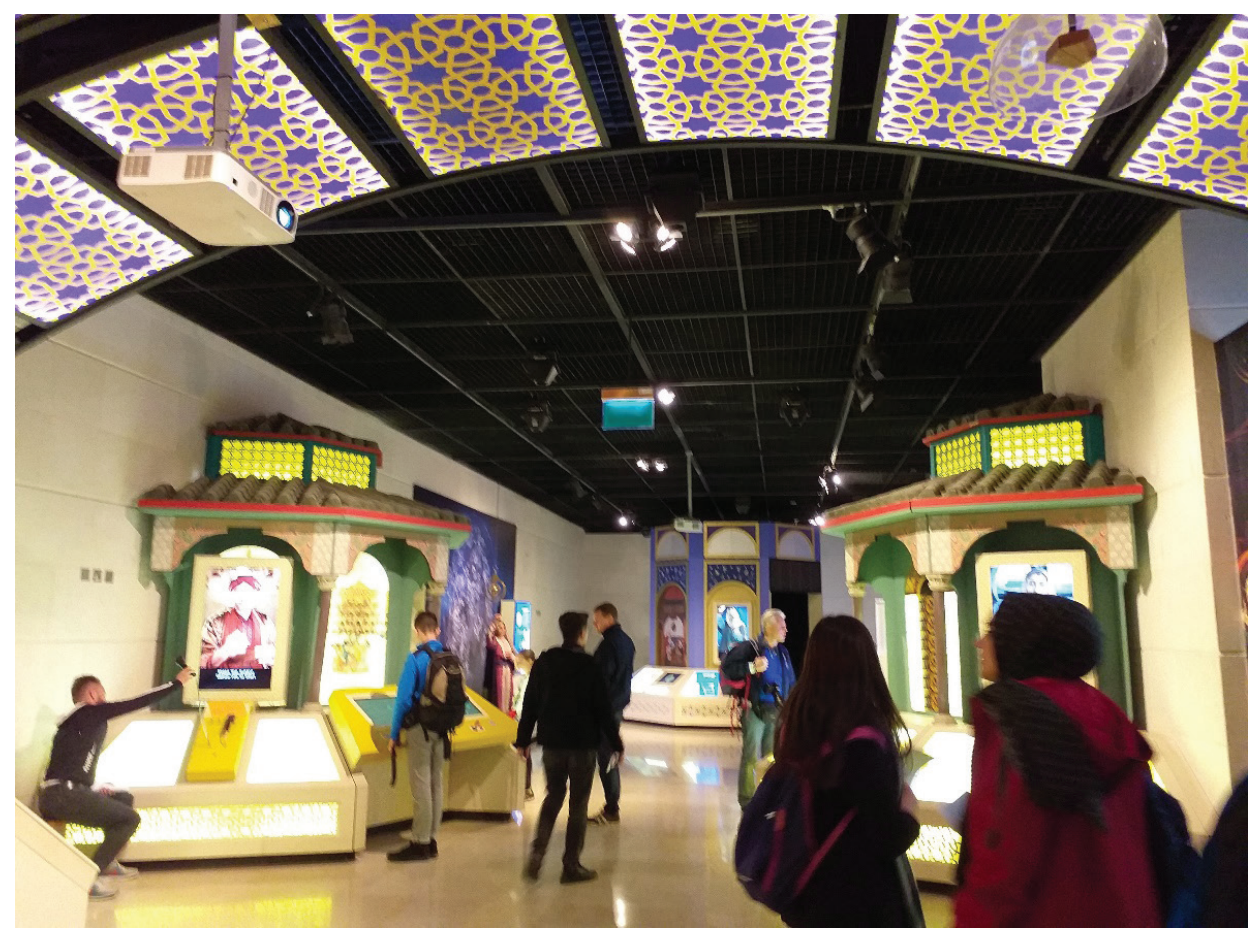

G. 4: Ürdün Müzesi 1001 Buluş sergi alanı (Ceren Güneröz, 2019)

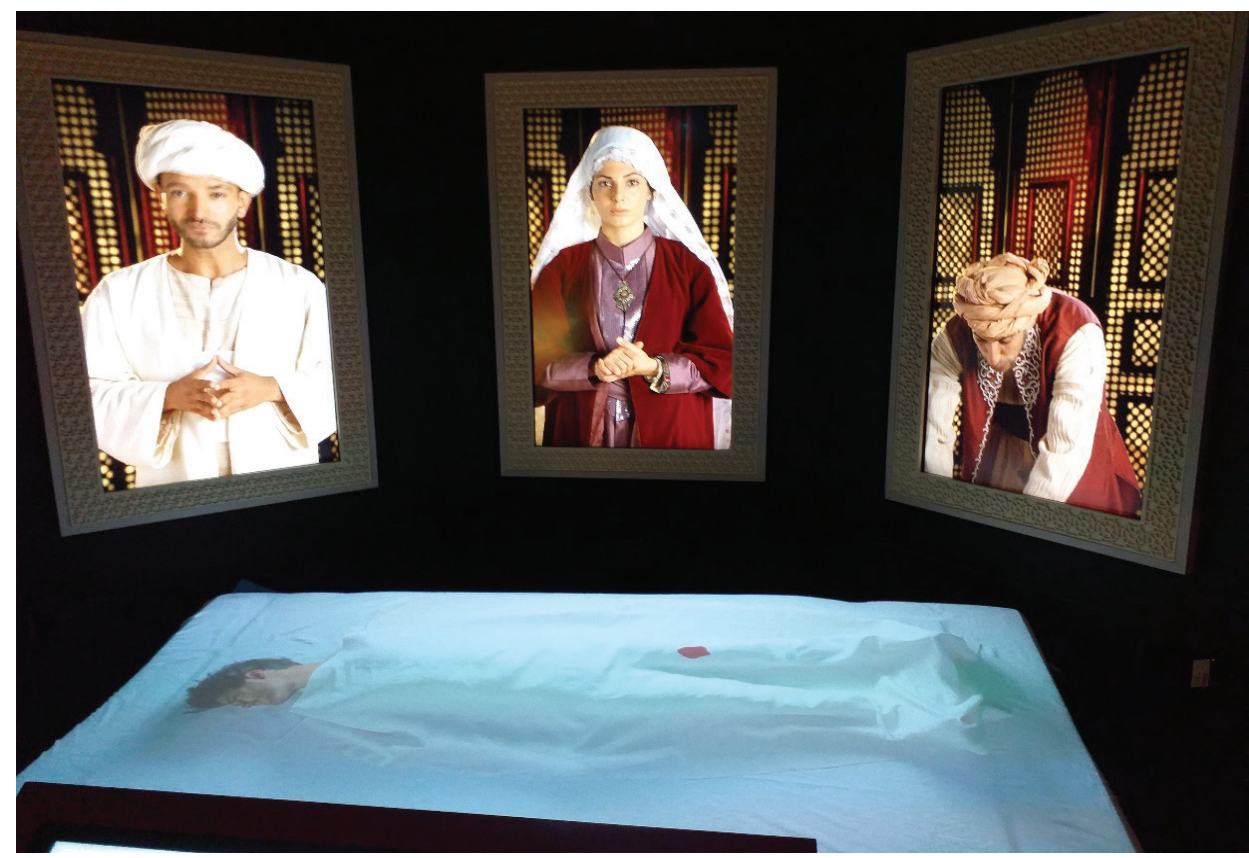

G. 5: Ürdün Müzesi Doğu’nun şifaları tıp tarihi etkileşimli sergi alanı (Ceren Güneröz, 2019) 


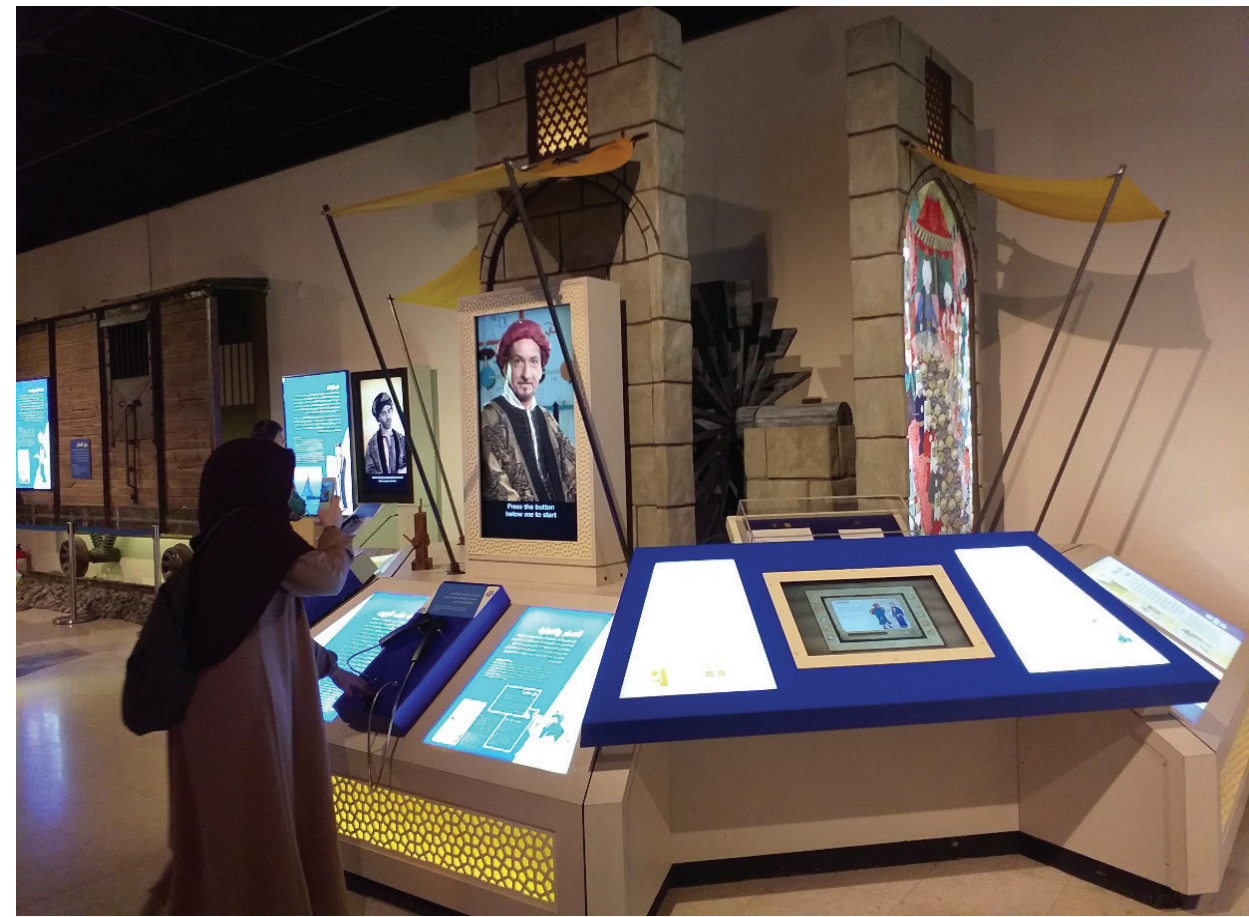

G. 6: Ürdün Müzesi 1001 Buluş etkileşimli sergi alanı (Ceren Güneröz, 2019)

2018 yılında Ürdün Kraliyet Tank Müzesi, 20.000 m²’lik bir alanda ziyarete açılmış bölgenin ilk tank müzesidir. Müzenin misyonu Ürdün Ordusu tanklarının ve savunma araçlarının modern Ürdün'ü şekillendirmede oynadıkları rol hakkında izleyicileri bilgilendirmek, koleksiyondan hareketle Ürdün tarihi hakkında ayrıntılı bir eğitim ve keşif deneyimi sağlamaktır. Müze, Haşim Ailesinin liderliğindeki Ürdün’ün geçmişte ve yakın tarihte yaşadığı savunma sorunlarını, savaşları ve savunma teknolojilerindeki gelişmeleri bu savaşlarda kullanılan savunma araçları aracılığıyla, diaromalarla ve videolarla anlatmaktadır. Müzede dünya savaşlarına tanıklık etmiş tanklar, Büyük Arap İsyanları, Ürdün Karamah Savaşı gibi gelişmeler diaromalarla ve dönemin savaş teknolojilerine ilişkin örneklerle sunulmaktadır.

Tank Müzesi’nin mimari planı, 1800’lü ve 1900'lü yılların dört sütunlu eski çöl kalesinden ilham alınarak tasarlanmıştır. Zırhlı tank tasarımının hacimli ve yavaş bir araçtan, çağdaş bir gizli silah sistemine nasıl dönüştüğünü yansıtmaya çalışan bina da gelenekselden moderne dönüşümü temsil etmektedir. Bu dönüşüm, geleceğin Ürdün'ünü mirasına bağlı çağdaş bir ülke olarak inşa etme amacını da yansıtmaktadır. Tank Müzesi, savaş teknolojilerine odaklanarak bölgede uzun zamandır devam eden siyasi ve askeri sorunların, savaşların ve krizlerin tarihini ve ayrıntılarını yansıtırken bir savaş tarihi müzesi özelliğini taşımaktadır. Bununla birlikte Osmanlı 
İmparatorluğu'na karşı başlatılan Büyük Arap İsyanını anlatan giriş diaromasında sunulan sahneler ise ulusal tarihi yansıtırken kültürün ve toplumların müzede temsili konusunu da gündeme getirmektedir (G. 7, G. 8, G. 9).

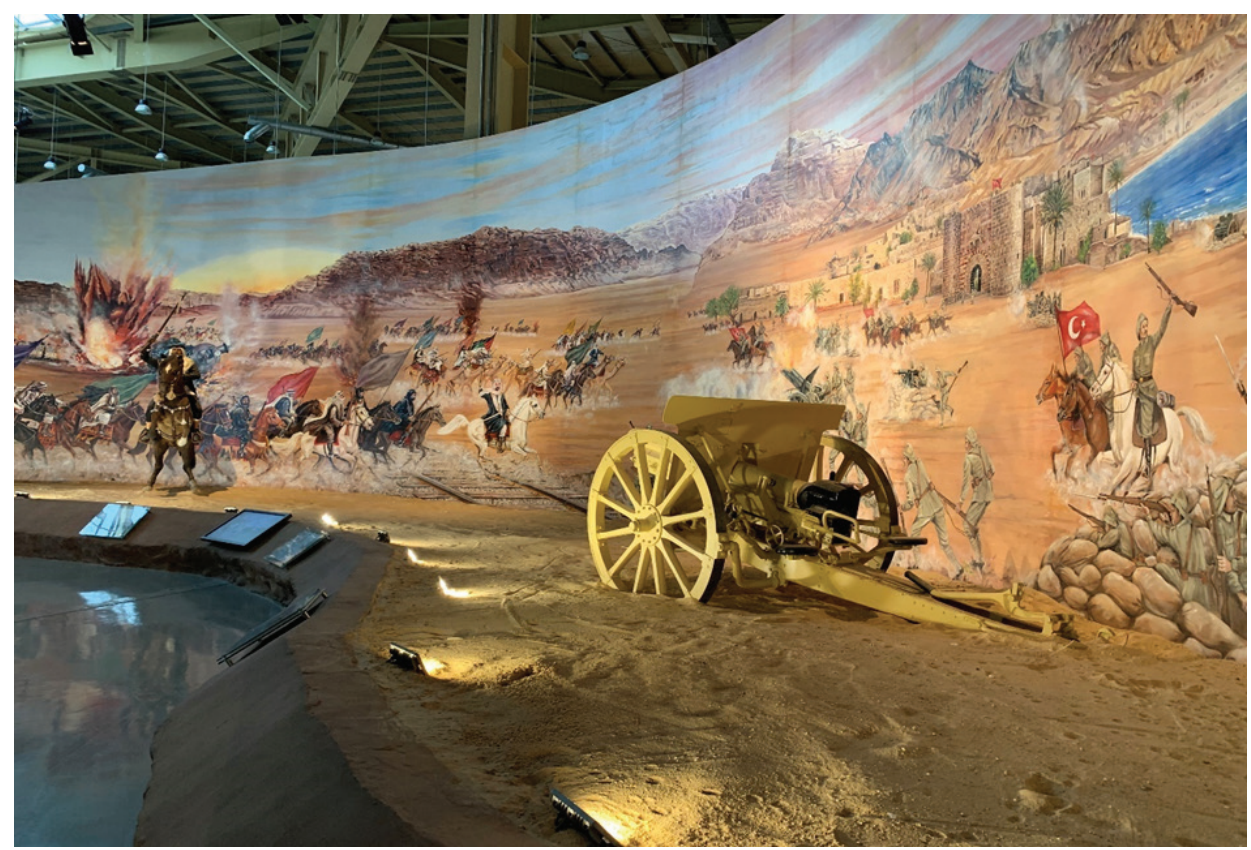

G. 7: Kraliyet Tank Müzesi Büyük Arap İsyanı Diaroması (Ceren Güneröz, 2019) 


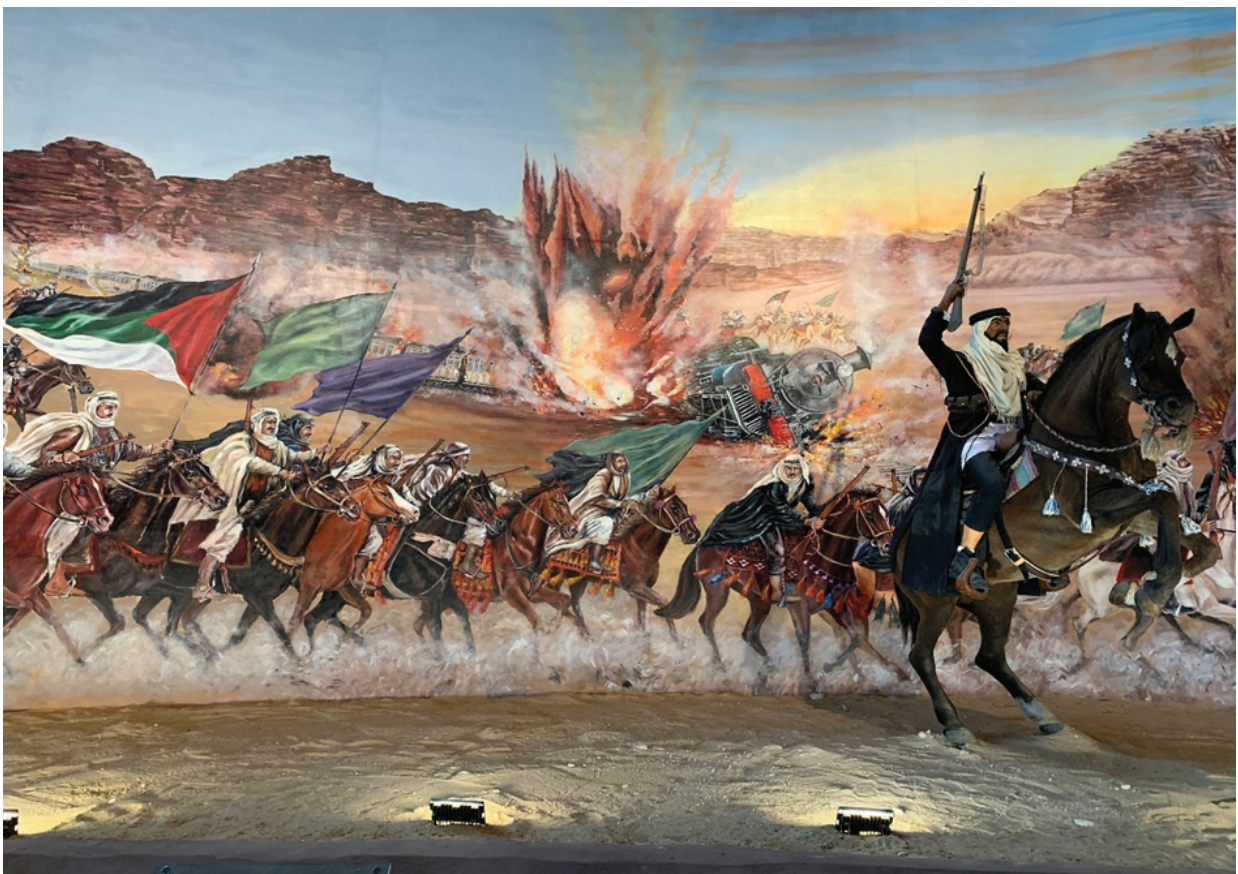

G. 8: Kraliyet Tank Müzesi Büyük Arap İsyanı Diaromasında Hicaz Demiryolu'nun tahribatı sahnesi (Ceren Güneröz, 2019)

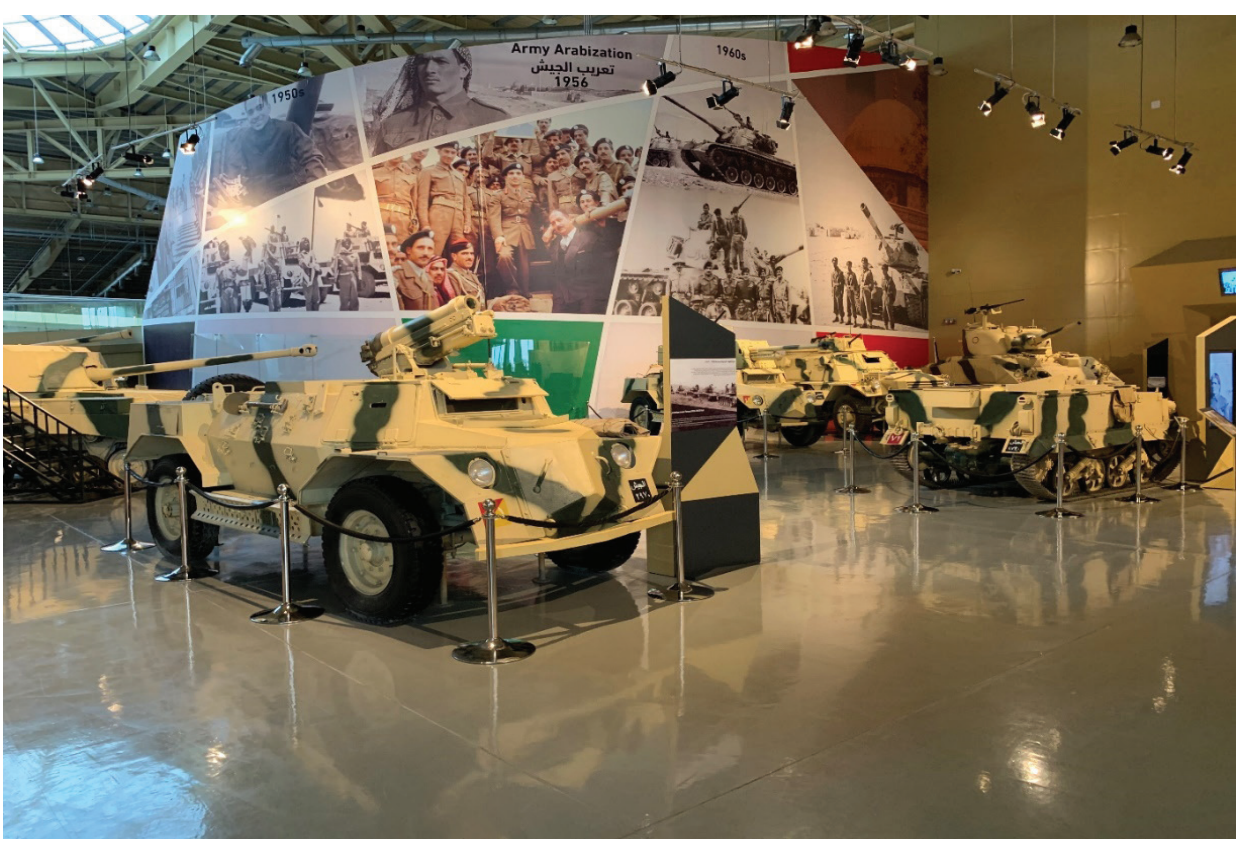

G. 9: Kraliyet Tank Müzesi Arap Orduları Yerleştirmesi (Ceren Güneröz, 2019) 


\section{Ürdün Müzelerinin Geleceği Sorunsalı}

Ürdün müzelerinin sayısı ve çeşitliliği artmaktadır ancak bu müzelerin hala mali zorluklarla ve nitelikli personel eksikliğiyle mücadele ettikleri söylenebilir. Belli başlı birkaç müze dışında müzelerde eğitim birimleri bulunmaması, teknoloji kullanımına ihtiyaç duyulması, müzelerle diğer kurumlar arasında iş birliği sağlanamaması, konferans ve seminer gibi tamamlayıcı etkinliklerin sayısının ve sıklı̆ğın az olması, müzelerin kültür-turizm sektörünün diğer kuruluşlarıyla rekabet etmede zorlanması, müze referans kaynaklarının eksik olması ve kültürel miras alanlarında yeterli kamuoyu oluşturulamaması en sık karşılaşılan sorunlardır. Bu sorunların üstesinden gelmek için Ürdün'deki müzelerin medya aracılığıyla tanıtımlarının yapılması, müze eğitim programlarının geliştirilmesi, referans kitapların hazırlanması, özerk yönetimin benimsenmesi, müzecilik eğitim merkezleri oluşturulması, finansal yardımların bulunması, sponsorluk etkinliklerinin geliştirilmesi ve koleksiyon yönetimi için yeni bilgisayar teknolojilerinin ve yazılımların etkin kullanılması gerekmektedir. Ajaj, bu sorunları Orta Doğu ülkelerindeki müzelerin genel sorunları olarak tanımlamaktadır ${ }^{50}$. Ürdün müzelerinin yerel topluluklarla ve öğretim kurumlarıyla etkileşim politikaları yoktur. Rida, öğrencilerin arkeoloji müzesi ziyaretlerinin etkililiğini incelediği çalışmasında Ürdün'deki müzelere ilişkin bir dizi sonuç çıkarmış; müze ziyaretleri öncesinde öğrencilerin eksik bilgilendirildiği, müze içinde eğitim etkinlikleri düzenlenmediği ve ziyaret sonrasında izleme çalışmalarının yapılmadığı sonucuna ulaşmıştır. Öğretmenlerin ziyaret ettikleri müzeler ve sit alanları hakkında ayrıntılı bilgiye sahip olmadıkları da vurgulanmıştır. İlgili çalışmada Ürdün Ulusal Eğitim Bakanlığı ile DOA arasında bir koordinasyon kurulmadığ izlenmiştir $^{51}$. Rida, aynı zamanda Umm Qais Arkeoloji Müzesi özelinde bir inceleme yapmış, müze ziyaretçilerinin \%60'ının öğrenciler olduğunu saptamıştır. Ürdün müzelerinin en büyük ziyaretçi grubu öğrenciler olduğuna göre eğitim konusundaki eksiklerini kapatmalarının önemli olduğu ortadadır.

Badran, Ürdün'de müzelerin gerçekleştirdikleri ilk eğitsel etkinliklerin rehberli müze turları olduğunu ifade etmektedir ${ }^{52}$. Ürdün Arkeoloji Müzesi'nde düzenlenen müze rehberli turlar dışında müzelerin çok azı okullara eğitim hizmeti sunmaktadır. 2007'de, Jerash Arkeolojik Müzesi, antik bir Roma firını kullanarak Roma usulü ekmek yaptırmış ve Roma zırhının nasıl kullanıldığını anlatan eğitimler hazırlamıştır. Müze 2012'de UNESCO Projesi'ne katılmış somut ve somut olmayan kültürel mirasın gençlere tanıtılmasına odaklanmıştır. Farklı bir yaratıcı eğitim programı 2011'de Kerak Arkeoloji Müzesi tarafından Kerak Kalesi’nde düzenlenen çizim yarışmasıdır.

50 Ajaj, "The Historical Development of University Museums in Jordan (1962-2006): Objectives and Perspectives Case Studies of Archaeology Museums at the Jordan and Yarmouk Universities," 80.

51 Nazımieh Tawfiq Rida, "School Visits to Archaeological Museums in Jordan," Proceedings of the Encounter Museums, Civilization and Development (Paris: International Council Of Museums, 1994), 183.

52 Arwa Badran, "The Excluded Past in the Jordanian Formal Primary Education: Introducing Archaeology," New Perspectives in Global Archaeology (New York: Springer, 2011), 198. 
İrbid $>$ deki Dar al-Saraya, orta avlusunda mezuniyet, tiyatro, y1llık festivaller, modern sanat sergileri ve drama gibi okul etkinliklerinin yanı sıra çeşitli derslerin verildiği müzelerden biridir. 2013'te Doğu Amman'ın Batı yakasıyla buluştuğu eski kent yerleşiminde Ürdün'ün yeni ulusal arkeoloji ve tarih müzesi olarak kurulan Ürdün Müzesi, bir eğitim politikası ve düzenli eğitim programı olan tek müzedir. Müzedeki sergi planının genel konsepti, Paleolitik dönemden modern zamanlara kadar Ürdün`ün hikâyesine odaklanmakta; eğitim çalışmaları öne çıkan eserlere odaklanmaktadır. Müzenin en önemli eserleri arasında Ayn Ghazal heykelleri, Tulaylat al-Ghassul duvar resmi, Pella fildişi kutusu, Khirbat adh-Dharih Nabataean heykelleri, al-Fudayn'ın bronz mangalları ve Ölü Deniz Parşömenleri bulunmaktadır. Eğitim personelinin de istihdam edildiği müzede düzenli olarak sanat konulu atölyeler düzenlenmekte; film gösterimleri yapılmakta ve konferanslar hazırlanmaktadır. Müze, Euromed Miras Programı gibi çok uluslararası projelere de ortaklık yapmıştır. Euromed Miras Programı; "Gelecek İçin Sağlam Temeller Atmak: Ürdün ve Lübnanlı Gençler Kültürel Miraslarının Güçlendirilmesine Katkıda Bulunuyorlar” isimli yerel bir projeye destek vermiş, Alamri ve Kafafi'nin aktardığına göre, Lübnanlı ve Ürdünlü gençlerin mirasla olan bağlantılarını güçlendirmeyi hedeflemiştir ${ }^{53}$. Dolayısıyla Ürdün Ulusal Müzesi'nin Ürdün müzeleri için çağdaş bir model olduğu ve müze gelişimi çerçevesinde öncü rol oynayacağı aşikardır.

\section{Sonuç}

Ürdün'deki ilk müze sömürgecilik döneminin izlerini büyük ölçüde taşısa da özellikle 1970'ten itibaren açılan müzelerde ülkenin bağımsızlık anlayışını temsil etme amac1, ulusal kültürü tanıtma ve kurgulama anlayışı ve toplumun kültürel mirasa ilişkin farkındalığını artırma çabası açıkça izlenmektedir. Kutsal Toprakların statüsü nedeniyle Filistin ve Ürdün>ün çeşitli bölgeleri kültürel mirasın zenginliği nedeniyle çağlar boyu özel ilgi görmüştür. Hristiyan misyonerler, çeşitli tarikatların mensupları ve dini nesnelere ilgi duyan koleksiyonerler bu bölgede kazılar yaparak kutsal toprakların kültürel mirasının korunmasında, tanınmasında ve batı ülkelerine transfer edilmesinde etkili olmuşlardır. Her ne kadar arkeolojik çalışmalar ve müzecilik etkinlikleri Filistin'de yoğunlaşsa da bu çalışmaların Ürdün'ü de olumlu yönde etkilediği kabul edilmektedir.

Ürdün'de müze kültürünün oluşturulması aynı zamanda halkın kültür, turizm ve yerel kalkınma gibi konularda bilgi sahibi olmasının sağlanmasıyla paralellik gösterir. Ülkenin ekonomik ve sosyal gelişiminin izleri müze olarak kullanılan yapılarda izlenebilir. Ulus inşası politikasının bir parçası gibi görünen Ürdün müzelerinin büyük bölümü ülkenin dünyaca ünlü arkeoloji mirasına odaklanmaktadır ve kullanılmaya

53 Yosha Alamri ve Jihah Kafafi, "The Jordan Museum, Storyteller of Land and People," Museums and the Ancient Middle East Curatorial Practice and Audiences (London: Routledge, 2018), 100-111. 
devam eden tarihi yapılar müze mekânı olarak tercih edilmiştir. İnşasına 1949’da başlanan Ürdün Arkeoloji Müzesi bunun en önemli örneğidir. Amman kalesinde kurulan müzenin 1951'de ziyarete açılmasının ardından 1970'e kadar açılan bir dizi müzenin yine arkeolojiye odaklandığı görülür. Ürdün'ün 1954'te UNESCO'ya katılması ve Lahey Sözleşmesi’ni imzalaması müzecilik etkinliklerini gündemde tutmuştur. Öte yandan DOA, 1960'tan itibaren arkeolojiyi ve miras bilincini yaymak için ülke çapında farklı sit alanları ve müzeler oluşturmaya çalışmıştır ve uluslararası iş birlikleriyle bu çalışmaları sürdürmektedir. 1970’ten sonra arkeolojik mirasın yanı sıra yerel halkın ilgisini daha çok çekeceği düşünülen etnografya ve yerel kültür koleksiyonlarının müze haline getirilmesi yaygınlaşmıştır. Bununla birlikte üniversitelerin eğitim amacıyla oluşturdukları koleksiyonları müze haline getirdikleri izlenmiştir. Bu müzelerin büyük bölümü ülkenin siyaset, kültür ve sanat başkenti konumundaki Amman'da ziyarete açılmıştır ancak 2000'li yılların başına kadar hiçbir müze girişimi Ürdün'ün en gözde turizm merkezleri olan Petra antik kenti, Ölüdeniz, Vadi Rum, Akabe, Nebo Dağ1 ve Madaba kenti kadar dikkat çekici olmamıştır. Bu nedenle özellikle Petra antik kenti ve Madaba kenti için deneysel arkeoloji çalışmalarını da içeren yeni nesil bir açık hava müzesi ve arkeopark hazırlıkları sürdürülmektedir (G. 10, G. 11, G. 12 ve G. 13).

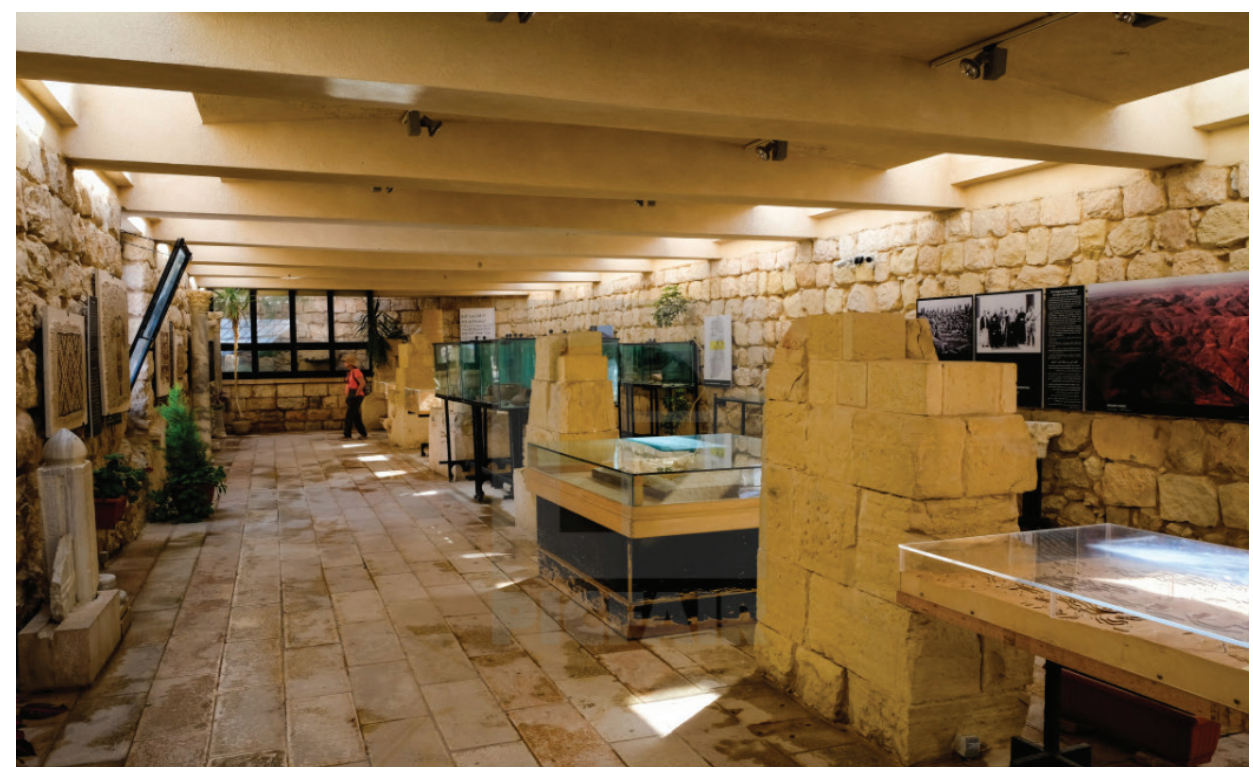

G. 10: Nebo Dağı Arkeoloji Müzesi sergi salonu genel görünüm (Ceren Güneröz, 2019) 


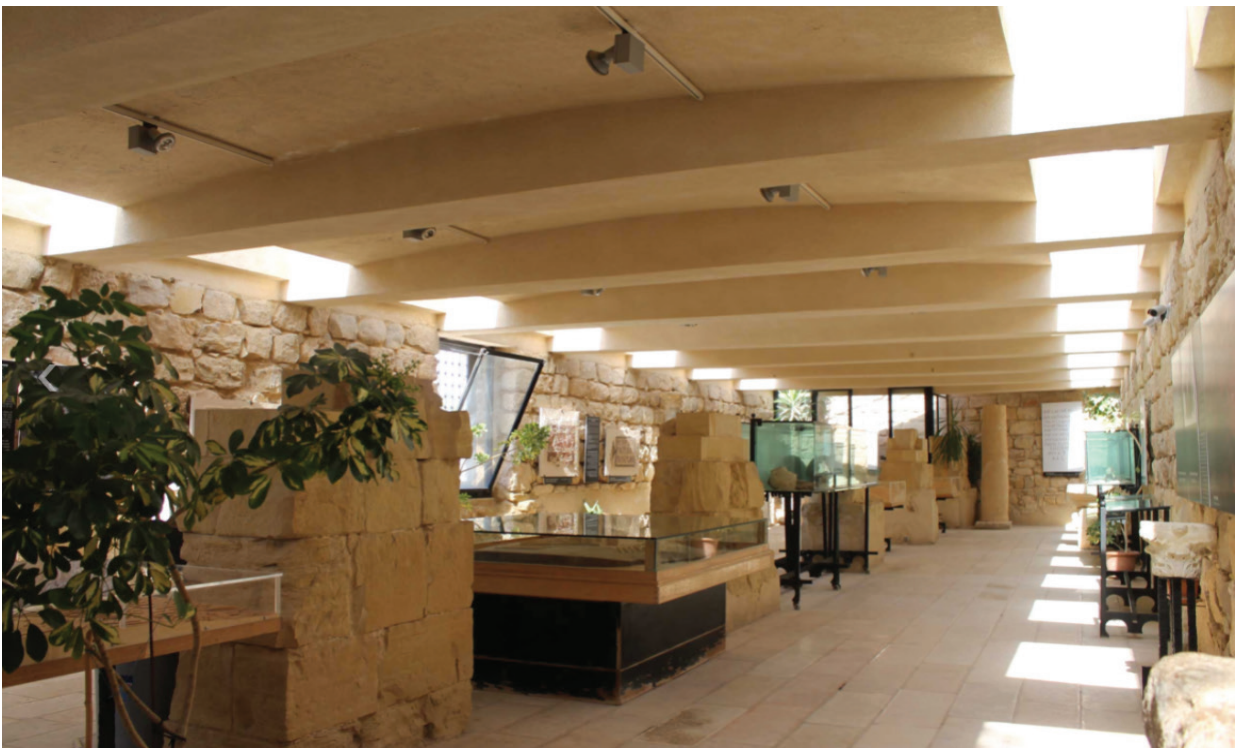

G. 11: Nebo Dağı Arkeoloji Müzesi sergi salonu genel görünüm (Ceren Güneröz, 2019)

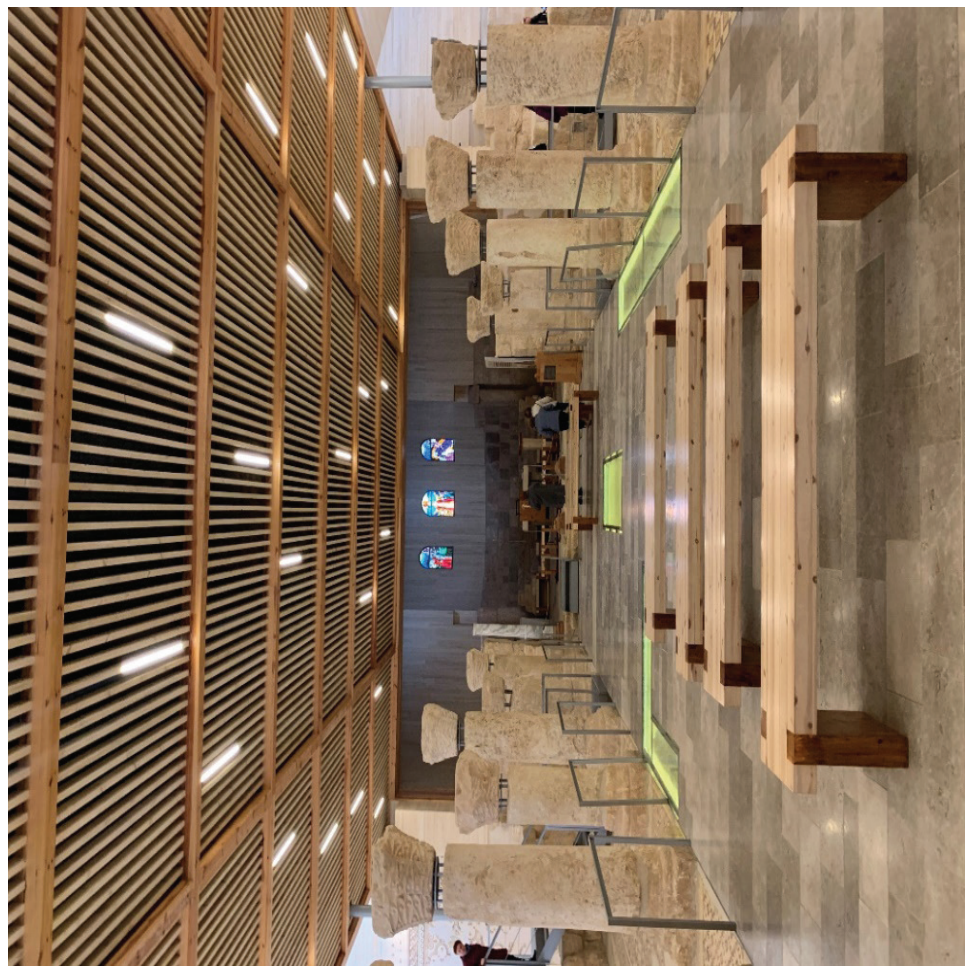

G. 12: Madaba Nebo Dağ1 sit alanı mozaikleri müze sergilemesi (Ceren Güneröz, 2019) 


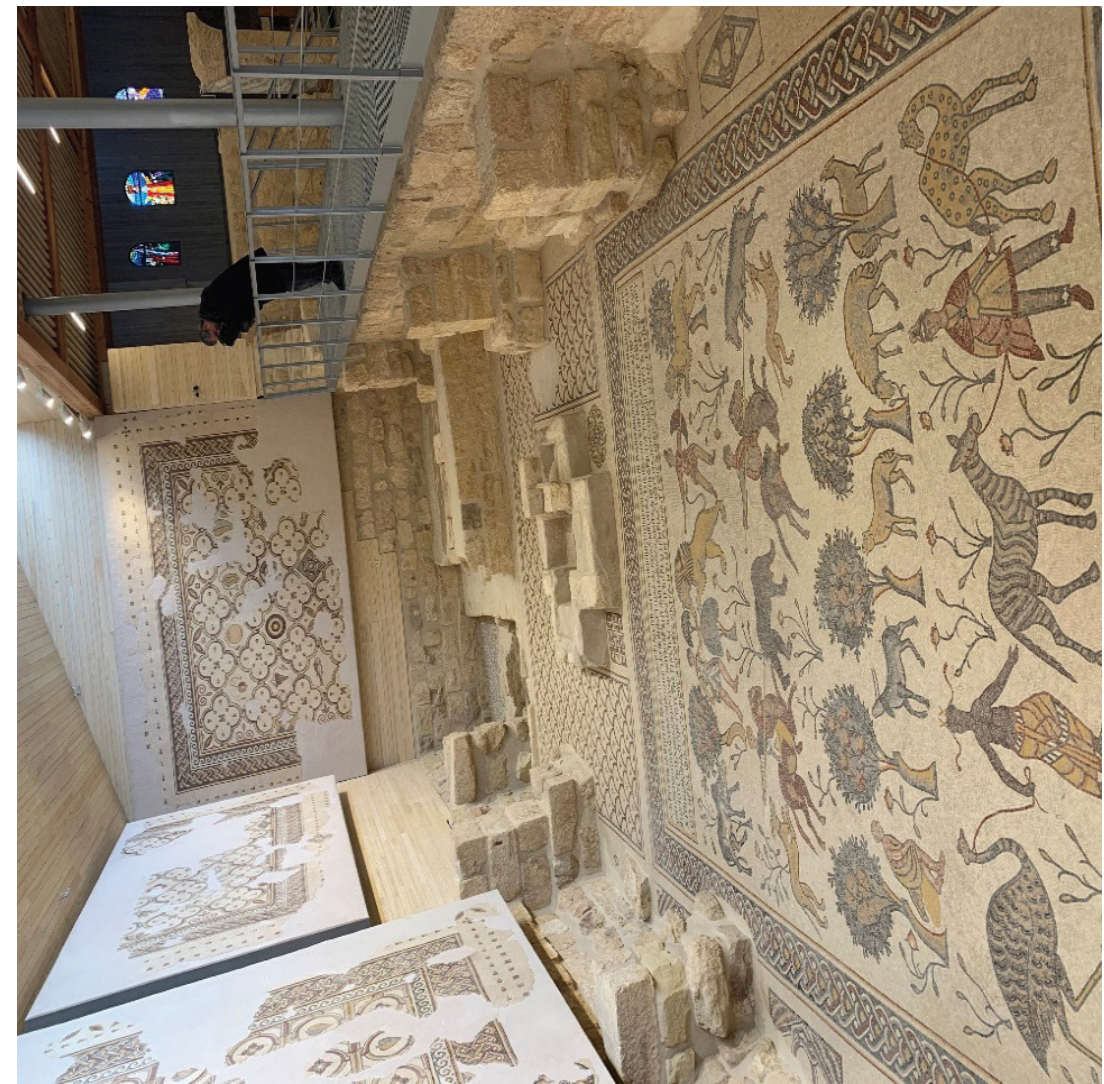

G. 13: Madaba Nebo Dağı sit alanı mozaikleri müze sergilemesi (Ceren Güneröz, 2019)

Ürdün'de müze çeşitliliğinin en çok arttığı dönem 1990 - 2000 yılları arası olmuştur. Arkeoloji ve etnografya müzelerinin yanı sıra tıp tarihi, veterinerlik, çağdaş sanat, din, demiryolu ulaşımı gibi alanlarda yeni müzeler izleyicileriyle buluşmuştur. Ürdün'de müze çeşitliliği ve sayısının artması bu kurumların çağdaş işlevlerle işletildikleri anlamına gelmez. Öyle ki, kolonist dönemin müzecilik anlayışı ülkede varlığını büyük ölçüde sürdürmekte; müzeler yerelde benzer mantıkla yönetilmekte ve halktan kopuk ve kapalı yapılar olarak daha çok yabancı ziyaretçilerin ilgisini çekmektedir. Ülkede müzelerde eğitim çalışmalarının yaygınlaştırılamaması bu durumun devam etmesine yol açmaktadır. Ürdün müzelerinin eğitim hizmetlerinde etkili hale gelmeleri için, şu evrensel önerileri göz önünde bulundurması gerekmektedir: Eğitimde kapsamlı bir planlama, düzenli ve değişken eğitim programının uygulanması ve değerlendirilmesi, eğitim materyalinin hazırlanması ve öğrenme alanlarının sağlanması, uzman eğitimciler istihdam edilmesi, gerekli finansal kaynakların sağlanması, farklı ziyaretçi topluluklarına uygun eğitim planlanması, okul-müze ortaklıklarının oluşturulması için miras ve eğitim sektörleri arasında işbirliği yapılması ve iletişimin kurulması, 
rehberlerin yetiştirilmesi. 2000'den sonra kurulan Ürdün Ulusal Müzesi ve Çocuk Müzesi gibi örnekler eğitim işlevini ve izleyici etkileşimini önemseyerek bu doğrultuda etkileşimli sergileri gündeme getirecek bir müzecilik anlayışı benimsemişlerdir. $\mathrm{Bu}$ anlayış özellikle Covid-19 salgınıyla birlikte duraksasa da ekonomik geleceğini kültür turizminde bulmaya çalışan Ürdün için başta Basra Körfezi'nin evrensel yeni müzeleri ve turizm anlayışı ile rekabetin gereği müzelerin sayısını ve çeşitliliklerini artırmak gerekmektedir. Bununla birlikte mevcut müzelerin durumlarını iyileştirecek bir ulusal kültür politikası benimsemek müzecilik alanında yapılacak çalışmalara yol gösterecektir.

Hakem Değerlendirmesi: Dış bağımsız.

Çıkar Çatışması: Yazarlar çıkar çatışması bildirmemiştir.

Finansal Destek: Yazarlar bu çalışma için finansal destek almadığını beyan etmiştir.

Peer-review: Externally peer-reviewed.

Conflict of Interest: The authors have no conflict of interest to declare.

Grant Support: The authors declared that this study has received no financial support.

\section{Kaynakça/References}

Abu-Khafajah, Shatha, Rama al-Rabady, Shaher Rababeh. "Urban Heritage "Space" under Neoliberal Development: A Tale of a Jordanian Plaza." International Journal of Heritage Studies 21 (2015): 441-459.

Ajaj, M. Ahmad. "The Historical Development of University Museums in Jordan (1962-2006): Objectives and Perspectives Case Studies of Archaeology Museums at the Jordan and Yarmouk Universities". Dissertation of Doctor of Philosophy, University of Leicester, 2007.

Alamri, Yosha ve Jihad Kafafi. "The Jordan Museum, Storyteller of land and people." Museums and the Ancient Middle East: Curatorial Practice and Audiences. Ed. Geoff Emberling and Lucas P. Petit. London: Routledge, 2018, 100-111.

Alawneh, Firas, Raed Alghazawi ve Fadi Balaawi. "Culture Heritage and the Idea of Jordan Museums.” Asian Social Science 8/7 (2012): 104-109.

Alshishani, Kamal. “Arkeolojik Alan Müzeleri Üzerine bir İnceleme: “İstanbul Arkeoloji Müzesi ve Ürdün Arkeoloji Müzesi Örneği.” Yüksek Lisans tezi, İstanbul Üniversitesi, 2018.

Badran, Arwa. "The Excluded Past in the Jordanian Formal Primary Education: Introducing Archaeology." New Perspectives in Global Public Archaeology, Ed. K. Okamura and A. Matsuda. New York: Springer, 2011, 197-216.

Bisharat, Suhail. "Museums, Collections and Collecting in the Arab World." The International Museum Management and the Curatorship 4/3 (1985): 279-287.

Bouchenaki, Mounir. "The Extraordinary Development of Museums in the Gulf States." Museum International 63/3-4 (2013): 93-103.

Boylan, Patrick. "Museums and Cultural Identity.” Museums Journal 90/10 (1990): 29-33.

Buzan, Berry ve Ole Wæver. Regions and Powers: The Structure of International Security. New York: Cambridge University Press, 2003. 
Department of Antiquties. "Brief History”. Erişim 13 Aralık 2020 http://doa.gov.jo/contents/briefhistoryar.aspx

Edhem, Halil. Modern Sanat Müzesi'nin Tasarımı: Müzecilik Yazıları. Ed. Ali Artun. İstanbul: İletişim Yayınları, 2019.

Hacıŏlu, Necdet ve Uğur Saylan. “Arap Baharı'nın Turizme Yansımaları: Arap Ülkeleri ve Türkiye.” Balıkesir University The Journal of Social Sciences Institute 17/32 (2014): 55-80.

Hitti, K. Philip. History of the Arabs from the Earliest Times to the Present. London: The Macmillan Press Ltd, 1974.

Hunter, F. Robert. "The Thomas Cook Archives for the Study of Tourism in North Africa and the Middle East.” Middle East Studies Association Bulletin 26/2 (2003): 157-64.

Garrison, Mark. "Antiquarianism, Copying, Collecting." A Companion to the Archaeology of the Ancient Near East. Ed. D. T. Potts. Oxford: Blackwell Publishing, 2012, 27-47.

Kafafi, Zeidan. "Who Owns the Past: Jordanian Archaeological Masterpieces at the International Museums." Studies in the History and Archaeology of Jordan 13 (2019): 627-640.

Karadeniz, Ceren. “Birleşik Arap Emirlikleri’nde Kültürel Miras ve Müzeler.” Yedi: Sanat, Tasarım ve Bilim Dergisi 20 (2018): 137-148.

Karadeniz, Ceren. "Katar'da Kültür, Miras ve Müze Çalışmaları.” Süleyman Demirel Üniversitesi ART-E Güzel Sanatlar Fakültesi Sanat Dergisi 12/24 (2019): 719-747.

Kennedy, David ve Robert Bewley. Ancient Jordan from the Air. London: The Council for British Research in the Levant, 2004.

Küçük, Cihan. “Louvre Abu Dhabi Açıldı: Körfez’in Evrensel Müze Teşebbüsü.” E-Skop Bülten 14 Ekim 2017. Erişim 15 Ekim 2017. http://www.e-skop.com/skopbulten/louvre-abu-dhabi-acildikorfezin-evrenselmuze-tesebbusu/3581\#_edn5

Kreps, Christina. "Appropriate Museology in Theory and Practice." Museum Management and Curatorship 23 (2008) 1: 23-41.

"Law of Antiquties." Erişim 1 Aralık 2020. https://www.unodc.org/res/cld/document/law-ofantiquities_html/Law_of_Antiquities-1-_jordan.pdf

Loftus Erskine. Pamela. "A Brief Look at the History of Museums in the Region and Wider Middle East." 2 A Architecture and Art Magazine Special Edition: Museums in the Middle East 13 (2010): $18-20$.

Malt, Carol. Women's Voices in Middle East Museums: Case Studies in Jordan. New York, Syracuse University Press, 2005.

Mubarak, Mohamed Al Khalifa ve Jean Luc Martinez. Louvre Abu Dhabi: Masterpieces of the Collection. Abu Dhabi and Paris: SKIRA Publishing, 2017.

Museum With No Frontiers. "MWNF-The Virtual Museums”. Erişim 20 Aralık 2020. http://www. museumwnf.org/

PEF, "Palestine Exploration Fund.” Erişim 12 Ekim 2020 https://www.pef.org.uk/about/history/

Petit, Lucas ve Geoff Emberling. Museums and the Ancient Middle East: Curatorial Practice and Audience. New York: Routledge, 2018.

Rida, Nazımieh Tawfiq. "School Visits to Archaeological Museums in Jordan." Proceedings of the Encounter Museums, Civilisations and Development. Paris: International Council of Museuma, 1994, 183-185. 
Sadeq, Mouin. "Archaeological Museums in Palestine: Reality and Prospective". Proceedings of the Encounter Museums, Civilization and Development, Paris: International Council Of Museums, 1994: 287-291.

Shaw, Wendy. Osmanlı Müzeciliği. Çev. Esin Soğancılar. İstanbul: İletişim Yayınları, 2020.

Suter, Claudia. "Gudea of Lagash: Iconaclasm or Tooth of Time?" Iconaclasm and Text Destruction in the Ancient Near East and Beyond. Ed. N. N. May. Chicago: The University of Chicago Oriental Institute, 2014, 57-88.

Scheltema, Gajus. Megalithic Jordan an Introduction and Field Guide. Amman: American Center of Oriental Research, 2008.

Thomason, Allison. "The Impact of the Portable Integrating Minor Arts into the Ancient Near Eastern Canon." Critical Approaches to Ancient Near Eastern Art. Ed. Brian A. Brown and Marian H. Feldman. Boston: Walter de Gruyter Inc, 2005, 133-157.

Yeşilyurt, Nuri. “Ürdün'ün Bölgesel Konumu: Küçük Devlet Kavramı Çerçevesinde Bir İnceleme.” Ankara Üniversitesi Siyasal Bilgiler Fakültesi Dergisi 70/2 (2015): 377-401. 